
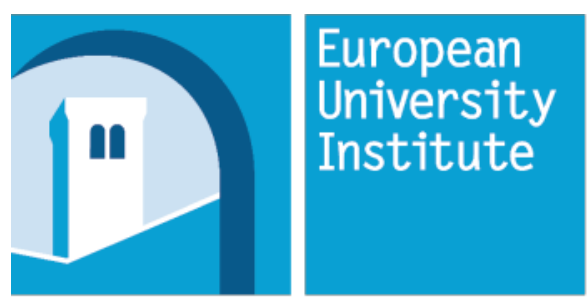

DEPARTMENT

OF

ECONOMICS
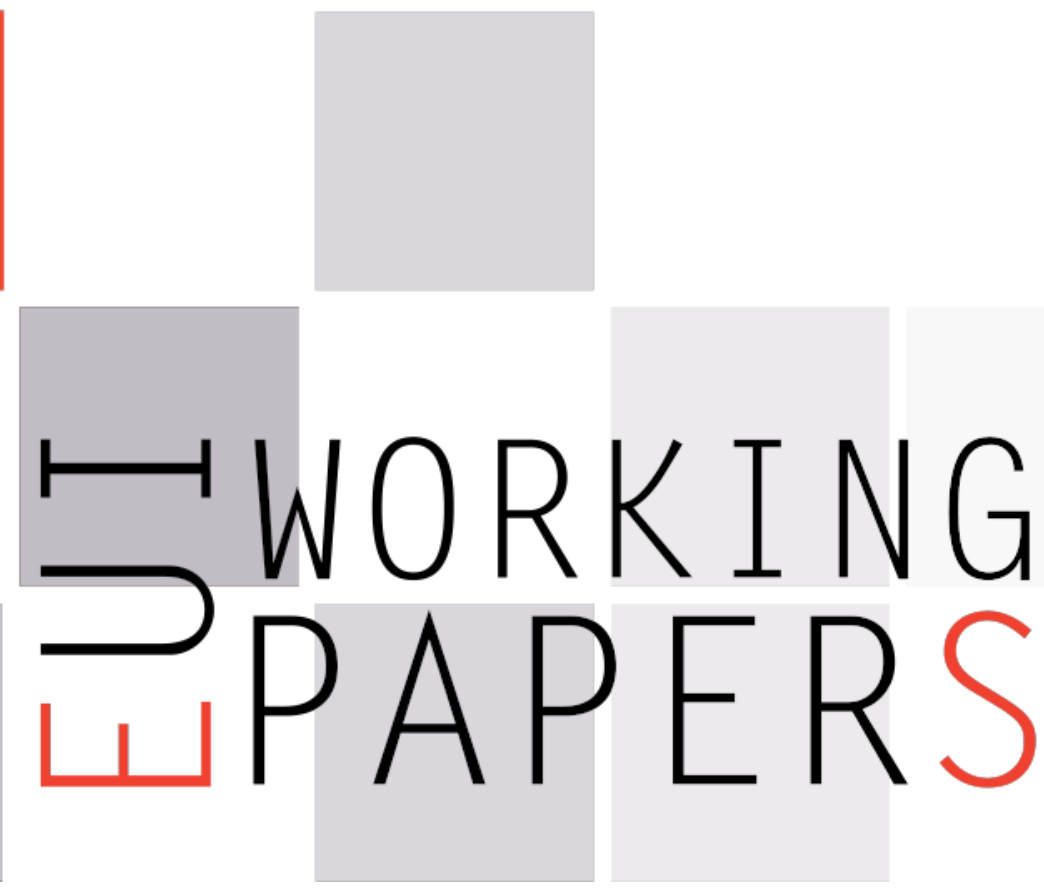

ECO 2016/13

Department of Economics

The Price of Growth:

Consumption Insurance in China 1989-2009

Raül Santaeulàlia-Llopis and Yu Zheng 

European University Institute

Department of Economics

The Price of Growth:

Consumption Insurance in China 1989-2009

Raül Santaeulàlia-Llopis and Yu Zheng

EUI Working Paper ECO 2016/13 
This text may be downloaded for personal research purposes only. Any additional reproduction for other purposes, whether in hard copy or electronically, requires the consent of the author(s), editor(s). If cited or quoted, reference should be made to the full name of the author(s), editor(s), the title, the working paper or other series, the year, and the publisher.

ISSN 1725-6704

(C) Raül Santaeulàlia-Llopis and Yu Zheng, 2016

Printed in Italy

European University Institute

Badia Fiesolana

I - 50014 San Domenico di Fiesole (FI)

Italy

www.eui.eu

cadmus.eui.eu 


\title{
The Price of Growth: Consumption Insurance in China 1989-2009*
}

\author{
Raül Santaeulàlia-Llopis \\ MOVE-UAB and Barcelona GSE
}

\author{
Yu Zheng \\ European University Institute \\ City University of Hong Kong
}

November 10, 2016

\begin{abstract}
The welfare gains of economic growth hinge on the ability of households to insure consumption against the risks associated with growth. We exploit a novel and unique opportunity to study this question using China, an economy that has witnessed enormous and sustained growth and for which we build a long panel of household-level consumption and income. We find that consumption insurance deteriorates along the growth process with a transmission of permanent income shocks to consumption that triples from 1989 to 2009. The loss of consumption insurance has implications for the welfare assessment of economic growth across time and across space.
\end{abstract}

Keywords: Income Risk, Consumption Insurance, Growth, Welfare, China JEL Classification: O4, D1

\footnotetext{
*We thank Sumru Altug, Loren Brandt, Omar Licandro, José-Víctor Ríos-Rull, Kjetil Storesletten, Gianluca Violante, Tao Zha, Xiaodong Zhu and the seminar participants at the NBER Income Distribution and Macroeconomics Group, NBER Aggregate Implications of Micro Consumption Behavior Group, NBER Chinese Economy Group, and many other venues. We would also like to thank Larenda Mielke and the alumni association of the Fudan-Olin MBA program for helpful discussions. Raül Santaeulàlia-Llopis thanks the Weidenbaum Center on the Economy, Government, and Public Policy for research funding 2012-2014. This project has also received support from the City University of Hong Kong Strategic Research Grant.
} 


\section{Introduction}

Countries that take off from poverty and begin to rapidly raise their standards of living are potentially subject to increasing income risks-i.e., unanticipated changes in income. This relation can arise from the new sets of projects and opportunities generating growth (Greenwood and Jovanovic, 1990; Greenwood et al., 2010; Cole et al., 2016). ${ }^{1}$ In this context, the ultimate purpose of growth, welfare improvement, hinges not only on growth per se but also on the ability of households to insure their consumption against the increasing risks associated with growth. We investigate this question by measuring the transmission of income inequality to consumption inequality for a country over a period of fast economic transformation: China from 1989 to 2009. During those twenty years, China has raised the income per capita by a factor of 6 , i.e., at 7.5 times the speed of the first industrial revolution. ${ }^{2}$ To the best of our knowledge, this is the first study that empirically explores the joint dynamics between consumption insurance and economic growth. To do so, we recover unique panel data on household-level consumption and income for a developing country that has successfully undergone sustained growth over a long span of years, i.e., an ideal scenario to study the relationship between growth, risk and insurance.

The phenomenal growth of China has spurred much academic research (Zhu, 2012; Storesletten and Zilibotti, 2014; Yao, 2014). However, it is hard to imagine that all households enjoy the same consumption path—then welfare-along the growth process. In particular, if household income risk increases with growth, the evolution of the ability to insure consumption against these risks is crucial to determine ex-ante households' welfare. This raises the following questions. First, how much does household income risk change during the economic growth? Second, how much does the ability to hedge against these risks change along this growth process? Further, in the context of China, with a system of public transfers that is based on the area of residency, how much do income risks and consumption insurance differ between rural and urban areas? These are the questions that we quantitatively answer here.

Our main finding is that economic growth is associated with more income risk and a loss of consumption insurance. We obtain these results in several steps. First, to be able to quantify income risks and insurance, one requires a panel of household consumption and income, a data requirement that is demanding even for the U.S. (Heathcote et al., 2010a; Carroll et al., 2014). In

\footnotetext{
${ }^{1} \mathrm{~A}$ positive relationship between income risk and growth can arise from the choice of risky projects that are more likely to yield higher income growth (Greenwood and Jovanovic, 1990). Alternatively, it is the presence of risky income that accelerate the accumulation of capital for precautionary reasons, which in turn leads to higher income levels (Krusell and Smith, 1998). Interestingly, the sign of the relationship between growth and risk might depend on the stage of economic development. Indeed, in an influential paper, Ramey and Ramey (1995) document a negative relationship between growth and volatility using a set of relatively rich OECD countries.

${ }^{2}$ It took the U.K. from 1820 to 1970 to raise the income by that factor (Bolt and van Zanden, 2013).
} 
the case of China, the data limitations are also important (Ligon, 2007). Our first contribution is the construction of a panel of household consumption and income in rural and urban China from 1989 to 2009. We build these measures from the China Health and Nutrition Survey (CHNS), a publicly available data source widely used for nutritional and medical research on China. ${ }^{3}$ The same data set has recently been used to study the effect of the housing reform-that privatized the housing market in China-on housing prices (Wang, 2011). We use a novel approach to construct food consumption from the Nutrition Survey, a core component of the CHNS that meticulously records the daily diet of all members in a household. Together with the local food price data from the Community Survey of the CHNS, we construct the value of diet, i.e., food consumption, for each household. We use the spatial deflator supplied by the CHNS that takes into account the important differences in price levels across rural and urban areas in different provinces. Compared with the official inflation numbers, the deflator we use implies slightly lower inflation from 1989 to 1997 and higher inflation from 1997 to 2009, a feature that is consistent with the evidence in Nakamura et al. (2016). With food consumption, the major component of nondurable consumption, and other pieces of nondurable consumption, services and semi-durables in hand, we consistently capture about $60-70 \%$ of a typical rural household's consumption basket and 50-60\% of a typical urban household's consumption basket. There are two important advantages from using a consumption measure largely based on food. First, it helps reduce potential measurement errors, a point that has been made to argue for the study of consumption insurance solely based on food (Attanasio et al., 2014). Second, it sets our results on the loss in insurance as a lower bound of such losses given that food consumption inequality tends to be lower than nonfood consumption inequality (Aguiar and Hurst, 2014). In terms of income, we use raw data from each household member to construct a measure of household income, consistent and harmonized across waves. Importantly, we separately recover the full set of public and private transfers received by all household members.

Second, the large set of potential insurance mechanisms that households can use in practice suggests that there might be not one but a combination of such mechanisms at work in order to explain the entire amount of risk sharing observed in an economy. Therefore, we opt to follow the premise in Deaton (1997) that calls for an assessment of the overall amount of risk sharing without specifying particular mechanisms (i.e., endowments, technologies or market arrangements). In this direction, we apply the proposed method in Blundell et al. (2008) to directly quantify how much of the permanent and transitory shocks pass onto consumption. ${ }^{4}$ Since we are interested in

\footnotetext{
${ }^{3}$ The CHNS is an on-going project between the Carolina Population Center at the University of North Carolina at Chapel Hill and the National Institute of Nutrition and Food Safety at the Chinese Center for Disease Control and Prevention. We discuss CHNS in great detail in section 3.

${ }^{4} \mathrm{An}$ alternative approach for studying risk sharing is to ascribe consumption behavior to a specific mechanism that structurally predicts distinct consumption responses to changes in income (Heathcote et al., 2009).
} 
the relationship of risk and insurance to growth, we allow both the income risk, i.e. the variance of the residual (or within-group) income inequality, and the consumption insurance parameters, i.e. the pass-through coefficients, to change over time.

We find that income risk has significantly increased with growth in rural and urban China from 1989 to 2009, and has remained the major component behind income inequality throughout the entire sample period. Our decomposition of income risks between permanent and transitory components reveals that a large part of the increase in residual inequality is driven by the permanent component, which is harder to insure and hence more costly in terms of welfare. At the same time that income risk rises with growth, we find that the ability to insure consumption has substantially deteriorated with growth. Precisely, while $12 \%$ of permanent shocks are passed to consumption in the $1990 \mathrm{~s}$ in rural areas, close to $30 \%$ of permanent shocks are transmitted to consumption in the 2000s. The transmission coefficient for the urban sample increases from $8 \%$ to $22 \%$. That is, the transmission of permanent income shocks to consumption has increased by a factor of almost 3 in the last decade, a significant worsening in the ability to insure consumption. The growth-insurance trade-off also holds across space between communities with high income growth versus communities with low income growth. High-growth communities experience both more risks and a larger deterioration in the ability to insure consumption over time. ${ }^{5}$ In terms of the transmission of transitory shocks to consumption, rural households show a high degree of consumption insurance over the entire sample period, a result consistent with the findings in the rural settings of poor countries (Townsend, 1994; Munshi and Rosenzweig, 2016). In contrast, urban households face a deterioration of consumption insurance against transitory shocks along the growth process, which is almost entirely mitigated by public transfers.

In an economy with high and increasing savings rates, it is natural to ask whether savings help fend off increasing permanent income risks. We provide evidence that the two predominant life-cycle savings in China in the form of investments in children and housing wealth-which represent three fourths of the total household wealth-are associated with reductions in the ability to insure. Investments in children are associated with an insurance loss against permanent risks in both rural and urban areas. Housing wealth, which is related to the urban housing reform in 1994, is associated with an insurance loss against permanent risks in urban areas.

Third, we use a unified framework for growth, risk and insurance similarly to Lucas (1987) in order to assess the welfare costs of growing with less insurance. We find these costs are large. In particular, rural households would actually prefer living under the growth-risk-insurance environment before the pro-market reforms than after the reforms, despite more growth in the

\footnotetext{
${ }^{5}$ See our Appendix.
} 
post-reform years. ${ }^{6}$ This suggests that currently the rural population is especially vulnerable to risks, where the social insurance provision (e.g. welfare programs, work subsidies and health insurance) has slowed down or disappeared. The case of urban households is different. The urban households have benefited from a change in the composition of public transfers from food coupons and work subsidies to pension income. This change decreases the co-movement between household earnings and public transfers, providing extra cushion for insuring consumption against shocks. ${ }^{7}$ In 2000s, the improvement in the insurance against transitory risks among urban households is the main reason behind the welfare gain of the post-WTO environment relative to the pre-WTO environment. Without public transfers urban households would also prefer the pre-WTO growth-risk-insurance environment.

Economic growth is related to the process of structural transformation (Gollin et al., 2002, 2004 ) that inevitably involves migration decisions. Re-conducting our welfare analysis across rural and urban areas, we explore how much risk and insurance affect the incentives to migrate along the growth process. We find that rural-to-urban migration entails consumption insurance losses that drop the welfare gains of migration by as much as $71 \%$ before the 2000 s. However, an increase in the amount of consumption insurance against transitory risk in urban areas in the 2000s substantially mitigates the loss in insurance and its effects on the incentives to migrate. The improvement in the insurance against transitory risk in urban areas is directly related to the composition of urban public transfers that shifts from being positively related to earnings in the 1990 s (e.g. food coupons and other work subsidies) to negatively related to earnings in the 2000s (e.g. pension income and welfare programs). Our analysis is related to the work of Harris and Todaro (1970) and an emerging development literature that emphasizes the joint importance of risk and insurance for migration decisions, see Bryan et al. (2014), Morten (2013), and Munshi and Rosenzweig (2016). ${ }^{8}$ In our case, from a macroeconomic perspective, we take advantage of a long panel of consumption and income for an economy that displays substantial growth to investigate the evolution of the welfare gains from migration along the process of economic growth. These gains largely increase with growth due to a change in the composition of public transfers that improves insurance in urban areas.

Finally, as China rebalances towards a consumption-based economy and relies increasingly on domestic demand, the GDP growth-targeting, which has for a long time dominated the policy agenda since Deng Xiaoping's growth reforms, is giving way to President Xi Jinping's integrated

\footnotetext{
${ }^{6}$ These pro-market policies encompass urban housing reforms, SOE reforms in the late 1990s, and culminate with the entrance of China in the WTO in 2001; see Section 2 for a detailed description.

${ }^{7}$ Fang (2014) provides a detailed description of insurance markets in China that includes pension income as an important component of social insurance policy.

${ }^{8}$ See an earlier discussion in Rosenzweig and Stark (1989) in which migration patterns through marriages across villages can help improve consumption insurance.
} 
approach that also values equity. In this direction, household income growth is recognized, for the first time, alongside the GDP growth as the political target of the Communist Party of China. Further, Premier Li Keqiang has repeatedly emphasized a "reasonable interval of growth which sustains stable employment and stable price levels," which some policy analysts view as preventive measures against social unrest. ${ }^{9}$ These political statements represent the search for a combination of growth-enhancing, risk stabilization and social insurance policies that preserve welfare, which is particularly relevant if China faces a future scenario of lower income growth (Higgins et al., 2016). We use our framework as a device to quantitatively assess the welfare implications of these three policies jointly-unlike previous literature that almost invariably studies them in isolation (see the discussion in Lucas (2003)). ${ }^{10}$

The rest of the paper is organized as follows. In section 2, we describe the evolution of institutions of social insurance in urban and rural China since Deng Xiaoping's growth reforms in the 1980s and the pro-market reforms in the late 1990s. In section 3, we describe the construction of the panel of household consumption and income. Further, we establish key facts about the evolution of rural and urban consumption and income inequality during the 20 years of economic reforms in China. In section 4, we measure the degree of partial insurance in rural and urban China. In section 5, we interpret these results with the additional information on investments in children and housing wealth. In section 6, we conduct a welfare analysis of growth, risk and insurance across time and space. Finally, in section 7, we conduct policy experiments that balance the trade-offs between targets of growth, risk and insurance representing the potential political tensions arising from future lower economic growth. Section 8 concludes.

\section{Institutional Background in China 1989-2009}

We begin by describing, in a highly parsimonious way, the growth model that China has taken since 1989. After a brief experimentation with economic liberalism in the 1980s, in particular in the rural areas, the Chinese government embarked on a highly controlled growth process in which resources were mobilized from the subnational governments to the central government, from the rural areas to urban areas and from the non-state to the state industrial sector. ${ }^{11}$ It channeled public resources away from the township and village enterprises (TVEs), popular in the 80s in the rural areas (Huang, 2008), and towards the state-owned enterprises (SOEs) in the cities (Song

\footnotetext{
${ }^{9}$ See Premier Li Keqiang's government work report at the National People's Congress in March 2014. He also commented along these lines in his visit to the UK on July 2nd, 2014, spurring a wide range of speculation about the upper and lower bound of the acceptable growth rates.

${ }^{10} \mathrm{~A}$ notable exception is Heathcote et al. (2014) that studies the joint effect of these three policies for the U.S.

${ }^{11}$ The central government "re-centralized" the tax revenue vis- $a$-vis the subnational governments by way of the 1994 Tax Reform, while largely leaving the expenditure responsibilities with the latter (Bird and Wong, 2005).
} 
et al., 2011). Within the state sector in cities, to concentrate effort in modernizing industries, the government strengthened the large state-owned enterprises by offering cheap loans and tax breaks and privatized a large number of small and effectively bankrupt enterprises to cut down loss. To facilitate the technological catch up, foreign investors with more advanced technologies (than their Chinese counterparts) were let in (Reenen and Yueh, 2012; Holmes et al., 2013). Millions of migrant workers, usually rural labor seeking off-farm work bound to their rural origin by the Hukou registration system, kept the labor cost low. Overall, this centralized approach has led to capital misallocation (Bai et al., 2006; Dollar and Wei, 2007; Hsieh and Klenow, 2009) and income inequality (Benjamin et al., 2008; Park, 2008). ${ }^{12}$

How does this development policy shape the income growth and risk environment that rural and urban households face? How does it affect consumption and welfare? Before moving on to precise measures of risks, insurance and welfare, we briefly comment next. By 1990, the agriculture output as a share of GDP had fallen from $40 \%$ in 1970 to $28 \%$, while its employment share had fallen from $81 \%$ in 1970 to $60 \% .{ }^{13}$ This means off-farm work has been an important source of income for rural households since 1989. In our sample, the agricultural income accounts for less than $50 \%$ of the total rural disposable income throughout the sample period (see Table 2 for 2006 for example). Apart from the risks inherent in agricultural production such as weather and input/output price risks, rural households are also, increasingly, subject to labor market and business income risks. If a member of a rural household seeks employment from a local TVE, he may face even higher risks than an urban employer working for an SOE given the deteriorating business environment for TVEs after 1990. On the other hand, the local social safety net is largely missing throughout our sample period. Since the Tax Reform, the county and township governments, supposedly the providers of public education, health care, medical insurance and infrastructure, have been paralyzed by fiscal imbalances. To solve their revenue problem, local governments turned to rural residents for extra budget fees and converted public assets and land to commercial uses, both of which essentially passed the financial burden onto rural households. Since early 2000, extra budgetary fees are cut and the pilot programs of new medical insurance scheme, social security and pension scheme are rolled out. Due to the limited coverage and scope of these pilot programs, the rural households in our sample had highly restricted access to public social insurance from 1989 to 2009. ${ }^{14}$

\footnotetext{
${ }^{12}$ See also the recent review in Fan et al. (2013).

${ }^{13}$ See Table 13.6 in Huang et al. (2005).

${ }^{14}$ The New Rural Cooperative Medical Scheme (NRCMS) pilot program was rolled out in 2003 and achieved almost full coverage in rural China in 2010, though the effectiveness of the medical scheme is questionable. See for example, Wagstaff, A., Lindelow, M., Wang, S. and Zhang, S., "Reforming China's Rural Health System", World Bank, Human Development (2009). The New Rural Social Security and Pension Scheme pilot program was initiated in 2009. On February 10th, 2014, the State Council announced the move to unify the pension systems for rural and urban residents in a meeting chaired by Premier Li Keqiang, paving the way for a unified factor
} 
In contrast, urban households have always enjoyed some public social insurance, though the composition of the social safety net have changed during the period of investigation. Up until mid1990, urban residents enjoyed a relatively stable state employment in a "work unit". The "work unit" provided a whole spectrum of services to the employees, ranging from housing, maternal care, child care, child education, and training to entertainment and health care. It distributed subsidies for food, commuting, heating (in winter seasons) and so on. The funding of the services and subsidies was partly from the work unit's revenue and partly from the government. Urban households faced relatively low income risks, and consumption was essentially guaranteed in an administrative process. The SOE reforms shook this old model of "enterprises running social programs" (qi ye ban she hui). To increase the profitability of the state sector, thousands of small loss-making SOEs were shut down or sold and their employees were laid off, ${ }^{15}$ and the remaining SOEs decreased their welfare spending on employees. Urban residents then not only faced higher unemployment and income risks, but also had to foot the bill for housing, child care and education and health service which had been given to them at low costs before. In particular, since the 1994 urban housing reform, state-employed urban residents were offered the opportunity to buy the apartments they had been renting from the state. This would later become a major form of wealth as well as a major channel of wealth accumulation for many an urban Chinese household. Meanwhile, the government started to build a social security system that includes unemployment insurance, health insurance (for the working as well as non-working urban residents) disability insurance and provision for retirement pensions.

The SOE reforms and the urban housing reforms that occurred in the late 1990s together with the entrance of China in the WTO in 2001 form the most important collection of pro-market reforms implemented by China in the 20 -year period that we study. For simplicity, in our analysis we will label the years before and after these pro-market reforms respectively as the pre-WTO era and the post-WTO era.

These institutional features and reforms have an impact on the evolution of the household income structure, in particular, in terms of the public transfers and their composition. ${ }^{16} \mathrm{We}$ compute the components of public transfers (i.e. food coupons, subsidies from work, subsidies from government and pension income) and the private transfers as a fraction of total household income from the CHNS and document their evolution in Figure 1. First, urban areas benefit more from public transfers than rural areas. The public transfers, in the aggregate, account for about $10 \%$ of the household income for the rural households, whereas it accounts for a much higher

market across the urban and rural parts of China.

${ }^{15}$ More than 21 million urban workers were laid off from the SOEs between 1999 and 2005 according to the official statistics released by the National Statistics Bureau.

${ }^{16}$ For data description and sample construction, refer to section 3. 
$30 \%$ for the urban households (i.e. the orange lines in both panels). In comparison, the role of private transfers is much less important for both rural and urban households throughout the sample period (i.e. the yellow lines in both panels). Second, the composition of public transfers has changed over time. Among the urban households, the role of subsidies for food in the form of food coupons and subsidies from the work unit decline visibly (i.e. the purple and blue lines in the urban sample). Meanwhile, the pension income becomes the major component of public transfers over the sample period (i.e. the olive line in the urban sample). ${ }^{17}$

\section{Consumption and Income Inequality: Evidence from the China Health and Nutrition Survey 1989-2009}

The China Health and Nutrition Survey (CHNS) is an ongoing data project conducted jointly by the Carolina Population Center at the University of North Carolina at Chapel Hill and the National Institute of Nutrition and Food Safety at the Chinese Center for Disease Control and Prevention. It is a panel dataset that tracks about 4,000 households in rural and urban areas of China from 1989 to 2009 . To the best of our knowledge, this is only publicly available household-level dataset from China that spans a significant period of economic transition.

We use the eight waves of CHNS conducted in 1989, 1991, 1993, 1997, 2000, 2004, 2006 and 2009. The sample encompasses nine provinces at different stages of economic development and with different natural endowments: Guangxi, Guizhou, Heilongjiang, Henan, Hubei, Hunan, Jiangsu, Liaoning and Shandong. In each province, a multistage random cluster process was used to draw the sample. ${ }^{18}$ Each year there are about 200 primary sampling units (PSUs), one third of which are in the urban area and two thirds in the rural area. Around 20 households were interviewed per PSU. This brings about 4,000 households in each year of the survey. In section 3.1, we briefly summarize the method we use to construct the household consumption and income panel. In section 3.2, we document some stylized facts about the consumption and income inequality in rural and urban China from the CHNS.

\footnotetext{
${ }^{17}$ From CHIP 1995 and 2002, the two waves that surveyed relatively completely the set of transfers, we do find somewhat similar evidence. In both urban and rural areas, pension became the dominant form of public transfers. In rural areas, the share of pension income in total public transfers increased from $59 \%$ to $82 \%$ from 1995 to 2002 and in urban areas, this figure increased from $90 \%$ to $94 \%$. Finally, private transfers are less important, as it is the case with CHNS.

${ }^{18}$ For more details of the the survey design, refer to the Design and Methods at the CHNS website: www.cpc.unc.edu/projects/china.
} 


\subsection{Data}

To study the degree of consumption insurance of Chinese households, we construct a panel of household consumption and income (with or without transfers) from the CHNS. Here we briefly discuss the construction of our measures of consumption, income, transfers, and household sociodemographic characteristics. ${ }^{19}$

The major non-durable consumption item in our analysis is food consumption. We construct household food consumption from the unique and highly detailed household-level dietary information from the CHNS. The Nutrition Survey, an integral part of the CHNS, documents the food items that a participating household consumes over a three-day window. The measurement of food consumption combines physical measurement of food items with daily interviews. The result is a highly detailed account of hundreds of types of food consumed on a daily basis, whose precision is suitable for nutrition studies and medical research (Batis et al., 2014). This survey design minimizes recall and telescoping error and can be considered as close as it gets to a "gold standard" for measuring consumption (Deaton and Zaidi, 2002; Beegle et al., 2010; Attanasio et al., 2014). ${ }^{20}$ The dietary data was published from 1989 to 2009, which defines the time frame of our sample. The nutrition survey is very comprehensive collecting consumption information for 636 food items from which nutrition intake information can be extracted. In addition to the food quantity data, we obtain the local food prices from the Community Survey. Harmonizing across the different categorizations used in the price and quantity data and across waves, we form the annualized value of the diet of the households. In addition, we also include in the value of diet the consumption of alcohol, tobacco, coffee and tea surveyed in the Household Survey but not in the Nutrition Survey. Our measure of food consumption matches well with the official statistics from the China Statistical Yearbooks (CSYBs) by year, province and urban or rural status. ${ }^{21}$ It is important to note that throughout our exercise we focus on expenditure-also pricing homeproduced food consumption - and do not distinguish between food expenditure and consumption (e.g. nutrient intake) as explored in Aguiar and Hurst (2005). We conduct robustness exercises using caloric intake as our consumption measure.

The CHNS collects data on additional consumption items such as utilities, child care, health

\footnotetext{
${ }^{19}$ We relegate the step-by-step description of each of these measures to Appendix A.

${ }^{20}$ Recently, Attanasio et al. (2014) have used several techniques to overcome measurement error problems. One proposed technique involves the use of consumption categories for which measurement error is known to be less of an issue. Analogous to what we do here, one of such categories includes the use of data from the dietary component of the Consumption Expenditures Surveys.

${ }^{21}$ While this is reassuring, it is important to note that our measure of food consumption is likely to be less subject to measurement error than that from the CSYB which requires annual recalls of food expenditures; see the paragraphs on "Food Expenditures" in Appendix A.4.1.
} 
expenditures, education expenditures, housing services, and semidurable supplies. Our measure of household consumption includes, in addition to food, the consumption of utilities, health service and semidurable supplies, items that are consistently surveyed in all waves. ${ }^{22} \mathrm{~A}$ look into the consumption basket of a typical Chinese household reported in the CSYBs suggests that these consumption items combined capture $60-70 \%$ of a rural household's consumption basket and $50-60 \%$ of an urban household's consumption basket. ${ }^{23}$

We construct measures of household income and transfers by source from the raw data. The household income measure is the sum of labor market income, agricultural income, business income and capital income, all after tax. The household transfer received consists of a public and a private component. The public transfer consists of the value of food coupons (from 1989 to 1993 when the coupon system was abolished), subsidies from the work unit (such as grocery, haircut and housing subsidies), subsidies from the government (such as utility and one-child subsidies) and pension income. ${ }^{24}$ The private transfer consists of cash and in-kind gifts from family and friends. The household disposable income is then the sum of the household income, public transfers and private transfers received. While the CHNS does not capture transfers given, the quantitative importance of private transfers is relatively minor compared with that of public transfers, see our discussion in the previous section about Figure 1.

In terms of sample selection, we focus on households whose heads are from age 25 to age 65 . This criterion is somewhat different from what has been used in the U.S. consumption literature. This is to accommodate the fact that the rural households, or about $70 \%$ of our sample, do not have a well-defined retirement age. In addition, we purposefully include the self-employed in the sample since most rural observations are of household farms. We exclude individuals with missing income or consumption and observations that report no food consumption. All economic variables are transformed to constant 2009 prices of urban Liaoning with the CHNS price deflator and then to the US dollars. We trim the top and bottom $1 \%$ of all sub-items of household consumption, income, and transfer measures and the household-level aggregates. ${ }^{25}$

\footnotetext{
${ }^{22}$ Our benchmark consumption measure excludes child care, as the child care expenditure is not available in year 2009. It also excludes housing service as it is only available from households that pay housing rent. See Appendix A.4.3 and A.4.5. Our results from the estimation of the partial insurance model in section 4 are robust to the introduction of child care expenditures and housing rents. We always exclude education expenditure, because it is only available in year 2006 .

${ }^{23}$ Table A-3 in the Appendix summarized the availability of sub-items of consumption and income across waves. Table A-4 in the Appendix reports the proportion of the expenditure on items represented in CHNS (i.e. food, durable supplies and health) in the total household expenditure from the CSYBs by year, province and urban status.

${ }^{24}$ It is worth noting that we did not use the imputed household income aggregates supplied by the CHNS, which we find has some serious data consistency issues, in particular in its non-retirement wage income. For a critique on the readily available household income aggregate, see Appendix A.2.1.

${ }^{25}$ This level-trimmed sample is the basis for documenting the evolution of consumption and income inequality
} 
Table 1 summarizes some key sample household socio-demographic characteristics. Our panel with replacement ages slightly from 1989 to 2009, with the average age increasing from 42 in 1989 to 49 in 2009. Households are predominantly headed by a male, especially so in rural areas. The educational attainment of household heads improves over time, with the percentage of rural household heads with no schooling decreasing from $13.6 \%$ in 1989 to $4.2 \%$ in 2009 and the percentage of urban household heads going beyond middle school (or the 9th grade) increasing from $36.9 \%$ in 1989 to $54.3 \%$ in 2009 . In terms of household structure, the average household size in rural areas increases from 4.31 in 1989 to 4.70 in 2009, while that in urban areas decreases from 4.04 in 1989 to 3.70 in 2009 . Consistent with the aging of the panel, the average weak dependency ratio, defined as the number of children (age below 15) over the number of adults (age above 15) decreases sharply from .48 in 1989 to .14 in 2009. The strong dependency ratio, defined as the number of children and old adults (age above 60) over all working-age adults (age between 15 and 60), also decreases from .66 to .32. In the rest of our empirical study, except when explicitly noted, we use equivalent scales as in Krueger and Perri (2006) to control for changes in the household composition. ${ }^{26}$

\subsection{Cross-Sectional Facts}

In this section, we document the joint evolution of consumption and income inequality using our constructed measures from CHNS for the period 1989-2009. While earlier studies on China's inequality focus on the distribution of either income or consumption separately (Khan and Riskin, 1998; Wu and Perloff, 2004; Benjamin et al., 2008; Li et al., 2012; Liu and Li, 2011), in our analysis we emphasize their joint dynamics.

over time in section 3.2. Since the estimation relies on the growth rates of residual income and consumption, to arrive at the estimation sample, we further trim based on the growth rates. We first construct the adult-equivalent household consumption and income (with and without transfers) from the level-trimmed data. Then we compute (logged) adult-equivalent household consumption and income residuals by removing, separately for each wave and area of residency, the effects of household characteristics that we consider permanent or pre-determined such as sex, age, education, province, and the pertinence to a minority group. Then we trim the top and bottom $1 \%$ of the growth rates of these consumption and income residuals and trim abnormal movements in growth rates for two consecutive waves. We provide full justification of our sample selection and trimming strategy and visualize the effects from each stage of trimming in Appendix B. The level-trimmed sample comprises on average 3,541 households per wave and the estimation sample comprises on average 2,215 households per wave.

${ }^{26}$ In the context of China, it is important to control for household composition as the interaction between coresiding adult children and parents might provide additional sources of insurance (Rosenzweig and Zhang, 2014; Oliveira, 2015). To compute the adult-equivalized disposable income, we divide by the number of working age adults in the household (i.e. those with age between 15 and 60). To compute the adult-equivalized consumption, we divide by the equivalence scales in Krueger and Perri (2006), defined as follows:

$$
K P=[\# \text { of adults age greater than or equal to } 15+0.7 \times(\# \text { of children age below } 15)]^{0.7} .
$$


Consumption and income growth. In Figure 2, we plot the household disposable income per capita and the household food expenditure per capita, conforming to the CSYB definitions to facilitate comparison with official statistics. ${ }^{27}$ Both income and consumption grow more in urban areas than in rural areas. In terms of disposable income per capita, we find a growth factor of 3.4 in rural areas and of 4.2 in urban areas over the 20-year period (see the top panels of Figure 2). Note that household income per capita growth is lower than the GDP per capita growth (indicated by the dotted line), an observation also made by Khan and Riskin (1998) from the China Household Income Project (CHIP) data. It is important to remember that what matters to counteract the rising income inequality and risks, which we document below, is growth in the household income, not necessarily GDP per capita. The top two panels show that the rural and urban household per capita net income growth in the CHNS aligns well with the official CYBS statistics. In terms of consumption per capita, we focus on food expenditures, its major component. We find a growth factor of 4.1 in rural areas and of 5.8 in urban areas between 1989 and 2009 (see the bottom panels of Figure 2). Note that the time series of food expenditures measures from CHNS also align well with the official CYBS statistics.

Consumption and income inequality. Table 2 gives an overview of the distribution of consumption, earnings (i.e., income without transfers), and disposable income separately for rural and urban areas in the 1989 and 2009 CHNS sample. The consumption gap between rural and urban areas is relatively small, urban households enjoy more consumption than rural households by a factor of 1.06 in 1989 and 1.10 in 2009 . The income gap is larger and grows with time. Urban households earn more disposable income than rural households by a factor of 1.39 in 1989 and 1.67 in 2009, a phenomenon that is partly generated by the increase in the transfers that urban households receive relative to rural households over time, which we can see by exploring the behavior of earnings. Urban earnings are higher than rural earnings by a factor of 1.04 in 1989 and 1.28 in $2009 .^{28}$

Consumption inequality is clearly less severe than income inequality in both rural and urban areas, which is suggestive of the presence of consumption insurance mechanisms in both rural and urban areas. In year 1989, the bottom $20 \%$ of the rural (urban) income distribution enjoy $18.3 \%(16.9 \%)$ of the total rural (urban) aggregate consumption, while the top $20 \%$ enjoy $22.9 \%$

\footnotetext{
${ }^{27}$ We subtract from the disposable income measure in the CHNS the value of food coupons and the in-kind gifts to make it comparable to official statistics. The definition of disposable income in CSYB is household total income minus taxes and fees paid, household operation expenses, depreciation of fixed assets for production and gifts to other relatives. We subtract from the food expenditure measure in the CHNS the value of food coupons and the food gifts to make it comparable to the official statistics. We apply the same deflator to both the CHNS and the CSYB series and normalize the real values in 1989 to 1.

${ }^{28}$ On average, a rural household receives more transfers than an urban household by a factor of 4 in 1989 and by a factor of 6 in 2009 .
} 
(22.7\%); see the top panels of Table 2 . This implies that the top $20 \%$ roughly enjoy 1.3 times more consumption that the bottom $20 \%$ in both rural and urban areas. The discrepancies are larger for income. The bottom $20 \%$ of the rural (urban) income distribution earn $4.1 \%(7.7 \%)$ of the total rural (urban) aggregate income, while the top $20 \%$ earn $45.2 \%$ (37.4\%). This implies that the rural (urban) top 20\% roughly earn 10 (5) times more income that the bottom $20 \%$. Moreover, there is clear evidence of increasing inequality in both areas, and more so in income than consumption; see the bottom panels of Table 2 for year 2009.

In Figure 3, we show the evolution of the raw disposable income and consumption inequality and the inequality measures adjusted for household composition. As shown in the left panel, in the rural sample the variance of logged raw disposable income increases from .8 in 1989 to 1.3 in 2009, which is about 3 times the size of its consumption inequality counterpart. Income inequality in urban areas is a bit smaller than in rural areas with a variance starting about .35 in 1989 and rising to about 1 in 2009. In the urban areas, the variance of consumption is about half that of income. The right panel shows the variance of income per worker and adult-equivalent consumption normalized at zero in 1989. Rural and urban samples display similar patterns of inequality with the variance of disposable income increasing by about .6 log points in the rural areas and .8 log points in the urban areas. That is, compared to the raw data, the adult-equivalent income inequality grows even more over time in urban areas than in rural areas. This is due to the fact that the covariance between income and number of adults decreases more in the urban areas than in the rural areas (see the middle panel). Regarding consumption, the variance of adult-equivalent consumption in China has increased by .3 in 20 years in both rural and urban areas. Both the level of income and consumption inequality as well as the growth are higher in China than those obtained for the U.S. using the CPS data. Overall, the increase in the variance of adult-equivalent income in the last 20 years in China is about two times the increase of its counterpart in the U.S. from 1970 to 2005, while the increase in the variance of adult-equivalent consumption is about three times its U.S. counterpart (see the top-left panel in Figure 13 in Heathcote et al. (2010b)). ${ }^{29}$

\footnotetext{
${ }^{29} \mathrm{As}$ a robustness check, we also compute the Gini index to describe inequalities (see Figure C-2 in the Appendix). The Gini of our adult-equivalent disposable income in rural areas increases from .40 in 1989 to .50 in 2009 and that in urban areas increases from .28 in 1989 to .44 in 2009. These numbers are similar to what Khan and Riskin (1998) and Li et al. (2012) find from the 1988 and 1995 CHIP surveys and what Li et al. (2012) find from the 2002 and 2009 CHIP surveys. The Gini of our adult-equivalent consumption in rural areas rises from .25 in 1989 to .35 in 2009, whereas that in urban areas rises from .27 in 1989 to .33 in 2009. That is, consumption inequality is about $2 / 3$ that of income inequality. This is in line with the Gini of the consumption surveyed in the CHIP dataset reported by Liu and Li (2011). For a discussion, see the paragraph on "Gini coefficients" in Appendix C.2. In contrast with previous literature, Cai et al. (2010) report, using the Urban Household Income and Expenditure Survey (UHIES), a similar (and for some years even somewhat higher) inequality of consumption compared with income inequality. We note that this is simply due to the fact that Cai et al. (2010) include durables in their definition of household consumption. Indeed, using only nondurable consumption from the Ur-
} 
Residual (within-group) consumption and income inequality. Three main findings stand out from our analysis. ${ }^{30}$ First, for both rural and urban households, the residual inequality explains most of the evolution of consumption and income inequality, accounting for roughly $90 \%$ of the overall inequality (see the left column in Figure 4). ${ }^{31}$ Second, residual income inequality grows twice as much as that of consumption from 1989 to 2009. To see this, we normalize the residual inequalities in 1989 to zero (see the middle column in Figure 4). Over time, the residual income inequality rises by almost .6 log points in rural areas and about .7 log points in urban areas. The residual consumption inequalities in rural and urban areas also rise, to about half the size of the residual income inequalities. The fact that the residual income inequality keeps rising indicates that both rural and urban households might be facing substantial permanent income shocks throughout the 20 years. The fact that the residual consumption inequality rises less than income inequality suggests that Chinese households have partial insurance, in the sense that they can smooth out some of the income shocks but not all. Third, the covariance of residual consumption and income more than triples over the span of 20 years (see the right column in Figure 4). While the covariance remains relatively constant for the first four waves, it keeps rising in the last four waves of the CHNS. In 2009, the covariance of residual income and consumption is three times as high as the 1997 level in both rural and urban areas of China. This is the first evidence that Chinese households are experiencing a deterioration in their ability to smooth consumption despite the income growth, which our quantitative exercise will confirm next. ${ }^{32}$

\section{Consumption Insurance in Rural and Urban China 1989-2009}

In this section, we estimate a partial insurance model using our constructed panel of consumption and income. This measures the size and time path of the variance of permanent and transitory risk, as well as the degree of the ability of Chinese households to insure against each type of risk. We present the model and the identification in section 4.1, and present the results in section $4.2 .{ }^{33}$

ban Household Survey (UHS), a subsample of the larger UHIES, we find that the adult-equivalent consumption inequality is about one-third to one-quarter lower than the adult-equivalent income inequality for the period 1993 to 1997 for which those data are publicly available. We find similar figures when we use the Rural Household Survey (RHS) for the period 1986 to 2000 for which those data are publicly available.

${ }^{30} \mathrm{We}$ explain the computation of the residuals in footnote 24 in section 3.1.

${ }^{31}$ Krueger and Perri (2006) decompose the rise in U.S. consumption inequality and find that about half of the rise in consumption inequality is due to residual (within-group) inequality.

${ }^{32}$ In Figure C-3 in Appendix C.2, we show that, in contrast, the covariance between residual consumption and income is fairly flat from 1972 to 1992 in the United States.

${ }^{33}$ As a preliminary exercise, we also conducted a full set of complete market tests à la Mace (1991) and Townsend (1994) with various measures of consumption and income assuming both CRRA and exponential utility. See Appendix G. 


\subsection{Measuring the Degree of Partial Insurance}

We estimate a partial insurance model à la Blundell et al. (2008) (henceforth, BPP). We regress the (logged) adult-equivalent income and the (logged) adult-equivalent consumption measure on dummies of sex, age, education level, province of residence and ethnic minority separately by urban status and by year, and take the difference of the residuals. For each household, we have the history of the (unexplained) income and consumption growth as inputs for the estimation.

The econometric model is annual and standard. The log (unexplained) annual income $y_{t}$ is the sum of a permanent component $z_{t}$ and a transitory component $\varepsilon_{t}$, that is, $y_{t}=z_{t}+\varepsilon_{t}$. The permanent component $z_{t}$ follows a random walk, $z_{t}=z_{t-1}+\zeta_{t}$. The shocks to the permanent component as well as the transitory component are i.i.d. across time and households: $\zeta_{t} \sim$ i.i.d. $\left(0, \sigma_{\zeta_{t}}^{2}\right)$ and $\varepsilon_{t} \sim$ i.i.d. $\left(0, \sigma_{\varepsilon_{t}}^{2}\right)$. $^{34}$

The measured log (unexplained) annual consumption growth $\Delta c_{t}^{*}$ follows:

$$
\Delta c_{t}^{*}=\psi_{\zeta, t} \zeta_{t}+\psi_{\varepsilon, t} \varepsilon_{t}+\xi_{t}+u_{t}^{c}-u_{t-1}^{c},
$$

where the preference shock $\xi_{t}$ is distributed as i.i.d. $\left(0, \sigma_{\xi_{t}}^{2}\right)$ and the measurement errors in consumption $u_{t}^{c} \sim i . i . d .\left(0, \sigma_{u_{t}^{c}}^{2}\right)$. The loading factors $\psi_{\zeta, t}$ and $\psi_{\epsilon, t}$ measure the degree of transmission of the two types of income shocks to consumption. They are interpreted as the insurance parameters against the permanent and transitory income shocks respectively. The higher the loading factor or the transmission, the lower the insurance. Perhaps, the most relevant aspect is to note that we allow for the variance of the income shocks and the partial insurance parameters to change with time. This non-stationarity provides the flexibility to fit the data from the rapidly growing economy of China, and allows us to study the joint dynamics between economic growth, risk and insurance.

Note that even though the model is cast in terms of annual income and consumption, the data points from the CHNS are not annual. To limit the number of parameters to be estimated, we restrict the loading factors $\psi_{\zeta}$ and $\psi_{\varepsilon}$ to be constant in the two subperiods, 1989-1997 and 19982009. The dividing line is motivated by the observation from the movement of the covariance of the residual consumption and income in Figure 4. In reality, the subperiod of 1989 to 1997 is one in which households still enjoyed relatively stable state employment and benefits, whereas

\footnotetext{
${ }^{34}$ The assumption of i.i.d. transitory shocks is motivated by the fact that the income data points are at least two years apart. We estimated a set-up where the transitory component of the income process follows an MA(1): $y_{t}=z_{t}+v_{t}$, where $v_{t}=\varepsilon_{t}+\theta \varepsilon_{t-1}$. We find that the persistence parameter $\theta$ is never significant and, hence, we simply set $\theta=0$ in our benchmark estimation. The fact that $\theta$ is not significant help us rule out the possibility that a deterioration in insurance (i.e., an increase in the loading factors) reflects a persistent transitory shock that we are not modeling.
} 
the subperiod of 1998 to 2009 captures the effects of the reforms (i.e., urban housing, SOE reforms, and the entry to the WTO) which fundamentally changed the economic lives of billions of Chinese. We derive in Appendix $D$ the identification of this annual model with a panel data set that has unevenly spaced survey dates and lay down the estimation procedure. The bottom line is as long as the sum of the variances of the permanent shocks is identified as a block, neither the identification nor the interpretation of the insurance parameters is affected by the unevenly spaced data. The model is estimated by the Diagonally Weighted Minimum Distance Estimator. In the subsequent tables of the estimation results, we report the sum of the variances of permanent shocks in between survey dates and the variance of transitory shocks in the survey year, the loading factors in the two sub-periods, the taste parameter and the measurement errors in consumption. Asymptotic standard errors are in the parentheses. ${ }^{35,36}$

\subsection{Estimation Results and the Role of Public and Private Transfers}

We estimate the partial insurance model using our benchmark measures of consumption and disposable income (i.e. earnings with both public and private transfers). Our main finding is that the ability to insure consumption against income risks has declined in both rural and urban areas, at the same time that income risks themselves have increased along the growth path.

In terms of income risks, both permanent and transitory risks increase across time, with a larger increase in urban areas (see the 'Disposable Income' columns in Table 3). More specifically, for rural (urban) households, the annualized variance of permanent shocks has increased from an average of .0913 (.0488) before 1997 to .1170 (.0887) after 1997, implying a 28\% (82\%) increase, while the annualized variance of transitory shocks has increased from an average of .3862 (.1999) before 1997 to $.4504(.2704)$ after 1997, implying a 17\% (35\%) increase. ${ }^{37}$ Across space, the rural households consistently face higher levels of permanent risks (and transitory risks) than the

\footnotetext{
${ }^{35}$ As a robustness check, we simulate our estimated benchmark model for 5,000 rural and urban households separately for 21 periods (i.e. 1989-2009) and verify that the variance covariance structure in the simulated data matches well that in our estimation sample. The estimates of the key moments from the simulated and original data with the standard errors are reported in Table E-1 in the Appendix. The estimates of the entire auto-covariance structure of income and consumption growth by survey year are reported in Tables E-2 to E-5 in the Appendix.

${ }^{36}$ In this paper, we choose to adopt the restricted income profile, an industry standard in the consumption literature (Blundell et al., 2008; Heathcote et al., 2014), to measure income risk. Importantly, we further allow the level of income risk and the degree of insurance to vary with time, i.e., with growth. An alternative modeling choice is the heterogeneous income profile with learning over own income growth pioneered by Guvenen (2007) and Guvenen and Smith (2014). The implications on consumption insurance of the uncertainty of own income growth in a non-stationary setting, i.e. along a growth process, is an interesting and challenging question that we leave for future research.

${ }^{37}$ The reported variance of the permanent risks in Table 3, to be consistent with the standard errors, is the sum of variances in between the survey dates. For example, a variance of .2238 for the rural sample in 1992-93 indicates an annualized variance of .1119 for the years of 1992 and 1993.
} 
urban households respectively by an average factor of 1.5 (and of 1.8 ).

In terms of insurance, both rural and urban households experience a worsening of insurance against the permanent risks from before 1997 to after 1997 (see the 'Disposable Income' columns in Table 4). The loading factor $\psi_{\zeta}$, which captures the percentage of permanent risks that is transmitted to consumption, increases from .1207 to .2968 for rural households and from .0766 to .2200 for urban households. This implies an increase in the loading factor for the rural and urban households by, respectively, a factor of roughly 3 . As to the insurance against the transitory risks, rural households achieve virtually perfect insurance throughout the sample period, whereas urban households' ability to insure improves from a $\psi_{\varepsilon}$ of .2116 to .0608 . This implies that while the insurance against permanent risks is similar for rural and urban areas, rural areas insure significantly better against transitory risks. ${ }^{38}$

To investigate the roles played by transfers on these insurance results across time and across space, we re-estimate the model with three alternative measures of income: earnings with private transfers, earnings with public transfers and earnings only. For the rural households, regardless of which income measure we use, the degree of transmission of permanent shocks shows similar deterioration over time, and the measured degree of transmission of transitory shocks is virtually nil throughout the sample period. The robustness of this result is not surprising given the little significance transfers have in the composition of household disposable income in rural China. ${ }^{39}$

In contrast, for the urban households, the public transfers have been a significant component of income for urban households throughout the sample period. In addition, the nature of the public transfers has changed over time. Public transfers in the early 90s, especially the subsidies from the work unit, are essentially a part of earnings. Urban households whose wage income is higher are also likely to receive a higher subsidy from their work unit, whether it be food coupons or subsidies for daily supplies or service (section 2). As the government function evolves, public transfers increasingly play the role of social insurance, such as pension and medical insurance, as well as welfare assistance. As a result, the public transfers received by urban households become less and less correlated with earnings or even negatively correlated with earnings over time (see Table F-1 in Appendix C.2). This has consequences for our results in urban areas.

\footnotetext{
${ }^{38}$ In the same direction as Aguiar and Hurst (2005), when we use caloric intake as our measure of consumption we find that the overall amount of consumption insurance is larger. Interestingly, when we use caloric intake as our measure of consumption the loss of consumption insurance over time is of similar size as the one that we find for expenditure.

${ }^{39}$ From 1989 to 2009 , the percentage of rural households that have reported a positive amount of public transfer decreased from $33 \%$ to $23 \%$. The same figures for the urban residents are $94 \%$ and $60 \%$. In terms of size, as a share of the aggregate income, the public transfers in the rural areas averages at about $10 \%$ while that in the urban areas averages at $30 \%$, over the sample period (Figure 1). The private transfers as a share of aggregate income is only $2 \%$ in both rural and urban areas.
} 
First, in terms of insurance against permanent risks in urban areas, the exclusion of public transfers significantly decreases (increases) the permanent income inequality before 1997 (after 1997). This implies, for a given consumption series, a higher (lower) loading factor before 1997 (after 1997) than the benchmark values (see columns under "Earnings + Private Transf." in Table 3 and 4). The urban point estimates for $\psi_{\zeta}$ are 0.1219 and 0.0704 for respectively before and after 1997. That is, public transfers tend to generate a loss of insurance against permanent risks over time in urban areas (see columns under "Earnings + Public Transf." in Table 4), while private transfers have the opposite effect. The overall effect is captured by "Earnings Only", the measure of income that removes both public and private transfers. Without transfers we find no major changes in the ability to insure against permanent risks in urban areas over the entire sample. This implies that with "Earnings Only" rural households are twice more able to insure permanent shocks before 1997 than urban households (respectively compare the estimates 0.1082 and 0.2038), while the opposite occurs after 1997 where rural households are less able to insure permanent shocks than urban households (respectively compare 0.2796 and 0.1788 ),

Second, in terms of insurance against transitory risks in urban areas, the result of a low insurance in urban pre-1997 China (compared with post 1997), holds only in the two specifications that have public transfers (see columns under "Disposable Income" and "Earnings + Public Transf." in Table 4). This implies that urban areas suffer a deterioration of consumption insurance against transitory risks (see columns under "Earnings + Private Transf." and "Earnings Only" in Table 4) that is only mitigated by public transfers. To understand this result, recall public transfers in the early 1990s are akin to in-kind transfers, and hence cannot be effectively saved for future consumption. Specifically, food coupons can only be applied to the purchase of designated food items and are valid for one year and utility subsidies must be deducted directly from the utility bill. This essentially imposes a savings constraint for households entitled to large public transfers in the $90 \mathrm{~s}$. As a result, consumption covaries positively and significantly with public transfers in the early 1990s (see Table F-1 in Appendix C.2). To put our intuition to the test, we reestimate the model with a measure of consumption that excludes the value of food coupons and the subsidy for utility as well as a measure of income that includes the earnings and the cash public transfers only, i.e. the welfare assistance and pension income. Now the urban households achieve almost perfect insurance against transitory shocks before 1997 and a similar loss of insurance after 1997, with a $\psi_{\varepsilon, p r e 97}$ of .0709 (s.e. .0587) and a $\psi_{\varepsilon, p o s t 97}$ of .1042 (s.e. .0505). ${ }^{40}$

To put our estimates in perspective, we compare our results with those in BPP. BPP obtain for the U.S. from 1979 to 1992 a loading factor of .6423 (s.e. .0945) for the permanent shocks and .0533 (s.e. .0435) for the transitory shocks using family disposable income and nondurable

\footnotetext{
${ }^{40}$ For the complete set of estimates, see Table F-2 in the Appendix.
} 
consumption. This way, the insurance against permanent shocks in the China appears to be higher than that in the US when, in fact, it is not. The main reason is that the major component of our consumption measure for China is food consumption, whereas this is not the case for the benchmark measure of nondurables in BPP. As BPP show, this has important implications for their results. Using only food consumption implies a lower degree of transmission of income risks to consumption. When only food consumption is considered, BPP find the transmission of permanent income risks is .29 in the US, which resembles our estimates for post-reform China. Hence, to the extent that the nondurable budget elasticity of food consumption tends to decline over time, the increase in the transmission from income risk to consumption that we estimate for China along its growth process is a lower bound of the actual deterioration of consumption insurance. For example, Aguiar and Hurst (2014) find food consumption inequality (in particular, home-produced food) is flat over the life cycle and attribute increases in inequality of life-cycle expenditures to other categories of nondurable consumption. ${ }^{41}$ To put it differently, if we observe a compromise in insuring food consumption in an environment where food consumption becomes increasingly a necessity, we would expect the consumption of other non-durable items to respond even more to income shocks.

In sum, Chinese households can partially insure against permanent shocks, a finding consistent with the results in Attanasio and Davis (1996), Blundell et al. (2008), Kaplan and Violante (2010) and Heathcote et al. (2014) for the U.S., and they can insure better transitory shocks than permanent shocks, in particular if we remove the in-kind transfers. What sets our results apart from previous studies is that we show the ability to insure income shocks worsens considerably with economic growth. ${ }^{42}$ First, the transmission from permanent income shocks to consumption triples in rural and urban China in the last 20 years. Second, the ability to insure against transitory shocks also significantly worsens in urban areas, but this loss is almost entirely mitigated with public transfers. Whether the welfare gains from growth are able to offset the welfare costs of higher risk and lower ability to insure in China is a question that we investigate in section 6. Before that, we investigate potential mechanisms behind our insurance results in the next section.

\footnotetext{
${ }^{41}$ In addition, we use adult-equivalent income and consumption measures, whereas BPP consider family net income and consumption (controlling for household structure in their computations of respective residuals). When only male earning is considered, BPP find a loading factor of permanent risks of .2245.

${ }^{42}$ In Appendix $\mathrm{H}$, we also explore the relationship between growth, risk and insurance cross-sectionally for communities with different growth rates. Our results suggest that communities that display higher growth are associated with increasing risks and a substantial worsening of the ability to insure, which are consistent with our benchmark estimation results.
} 


\section{Theoretical Interpretations of Insurance Behavior}

In a country known for its high household savings rates, it is natural to ask whether savings help fend off household income risks. ${ }^{43}$ In this section, we explore how two well-known forms of life-cycle savings that are predominant for Chinese families, investment in children (Banerjee et al., 2014) and housing wealth (Wang, 2011; Wei and Zhang, 2011)—which potentially crowd out precautionary saving, help understand our main result in section 4.2 that shows a clear deterioration of consumption insurance against permanent risk.

\subsection{Investment in Children}

The notion of life-cycle savings, in its original form and in an exposition for China by Modigliani and Cao (2004), is that households save for retirement. In the absence of a well-functioning pension system in China, children have traditionally been considered as the old age security. In this context, the One-Child Policy that restricts the number of children a family can have can trigger both a quantity-for-quality trade-off (Rosenzweig and Zhang, 2009) and higher savings as households postpone consumption to make up for fewer future income providers when old (Banerjee et al., 2014). ${ }^{44}$ In this section, we recognize the intensive margin of investment in children, i.e. the expenditure on education, as a form of life-cycle savings and ask how the strength of this form of savings affects the degree of consumption smoothing.

To measure investments in children, we compute the education-expenditure-to-saving ratio in 2006 and group those households whose ratio is above (or below) the median as high (or low) investment households. ${ }^{45}$ Note that our measure of savings is the difference between the household disposable income and benchmark consumption, the latter of which does not include

\footnotetext{
${ }^{43}$ Precautionary motives based on prudence (Kimball, 1990; Carroll and Kimball, 1996), on impatience (Carroll, 1997) or on institutions that impede borrowing (Deaton, 1991; Aiyagari, 1994; Rios-Rull, 1995; Huggett, 1996; Carroll and Kimball, 2001) raise savings in response to higher income risk. As documented in the previous section, China has seen an increase in unanticipated income changes in both rural and urban areas, which can potentially help explain the rise of household savings in China. For example, Meng (2003) discusses an increase in savings associated with the increased predicted risk of unemployment and the increased past income uncertainty during the state-owned enterprise (SOE) reforms in the late 1990s. Chamon et al. (2013) find an increase in the savings rates of young urban households that they attribute to an increase in labor income uncertainty; see also Yu and Zhu (2013) for a discussion of an increase in uncertainty in household income using CHNS imputed income data. More recently, He et al. (2013) study the SOE reforms in the late 1990s in urban China, finding a subsequent increase in financial wealth accumulation.

${ }^{44}$ See Qian (2009) for a discussion on the potential complementarities between quantity and quality as the family size changes with the relaxation of the One-Child Policy.

${ }^{45}$ The education expenditure is only surveyed in the 2006 wave of the CHNS. In the CHNS data, the education expenditure as a share of household income is 12.2\% (9.94\%) in rural (urban) areas in 2006. In the CHIP dataset, this ratio increases from 8.15\% (5.75\%) in 1995 to 13.35\% (8.95\%) in 2002 in rural (urban) areas. These pieces of evidence portray a general increase in the investment in child's education.
} 
education expenditures. The idea is that households that spend a higher fraction of their savings on educating their children will have less of a buffer against income shocks. ${ }^{46}$

The partial insurance estimates are found in Table 5. Households whose investments in children are low do not experience a deterioration in the ability to insure against permanent shocks over time, while those households whose investment in children is high show a clear deterioration in both rural and urban areas. In the rural areas, while $\psi_{\zeta}$ shows no significant change over time for households with low investments in children, this loading factor increases significantly from .1331 in the pre-1997 years to .5260 in the post-1997 years for households with high investments in children. Similarly, for urban households, this loading factor is never significantly different from zero for households with low investment in children, while it increases from virtually perfect insurance in the pre-1997 years to .5124 in the post-1997 years for households with high investments in children. That is, in both rural and urban areas, high investment in children is clearly associated with the deterioration of the insurance against permanent shocks attained in our benchmark results. Our results suggest that it is unlikely that Chinese households give up investments in children for a better insurance against permanent risk. ${ }^{47}$

\subsection{Housing Wealth}

The housing reform implies that since 1994 urban households have a new avenue to invest their wealth (section 2). Since then, housing wealth has become the most important form of savings for Chinese households. This way, the housing wealth (net of debt) accounts for $68.1 \%$ of total net worth in urban areas in 2011. This share is about 3 times larger than that obtained for the U.S. (see Table 7 in Díaz-Giménez et al. (2011)). ${ }^{48}$ But houses are relatively illiquid assets that

\footnotetext{
${ }^{46} \mathrm{We}$ also repeated this exercise using the expenditure on child care, available from 1989 to 2006 . Here we qualify a household with high investment in child care a household whose expenditure-to-saving ratio is above median in any given survey year. We obtain similar insights.

${ }^{47}$ While our focus is on permanent risk, we also find that investments in children do not affect the insurance against transitory shocks which in rural areas is always high and in urban areas is somewhat moderate. This is consistent with our results in the previous section that show that public transfers almost entirely mitigate the loss of insurance against transitory earnings shocks.

${ }^{48}$ While in rural areas housing wealth has always been an important component of household wealth, the 1994 urban housing reform which privatized the state-owned housing and established private housing markets set in motion a rapid accummulation of housing wealth among urban households. From the China Household Finance Survey (CHFS), housing wealth (net of debt) accounts for $82.1 \%$ of total net worth in rural areas and $68.1 \%$ in urban areas in 2011. These shares are about 3 times larger than those obtained for the U.S. (see Table 7 in Díaz-Giménez et al. (2011)). Most notably, the financial wealth is still a relatively minor component of household wealth in China. The ratio of housing wealth to financial wealth in the CHFS is 7.55 in 2011 and 6.57 in 2013 (see the CHFS staff report: http://econweb.tamu.edu/gan/April-2014-English.pdf). Using a third data source, CHIP, we find that this ratio of housing wealth to financial wealth is 11.17 and 5.34 , respectively, for rural and urban areas in 1995 and 8.67 and 5.39, respectively, for rural and urban areas in 2002. In our dataset, the percentage of home ownership in rural areas has varied from $91.6 \%$ in 1989 to $96.3 \%$ in 2009 and that in urban areas has increased rapidly from $45.7 \%$ in 1989 to $89.2 \%$ in 2009 . The CHNS surveys home ownership and
} 
are less likely to be used to insure consumption. It is interesting then to investigate whether this mechanism helps explain the loss of consumption insurance in urban areas.

Our results are in Table 6. Perhaps not surprisingly, in rural areas, where the housing reform did not occur, we do not find differences across housing-wealth groups. Dividing our sample into low and high housing-wealth (i.e., respectively, below and above the median housing wealth), we find that both groups display a deterioration in the insurance against permanent risk, increasing the loading factor $\psi_{\zeta}$ roughly by a factor three. That is, the life-cycle savings in the form of housing do not contribute to the consumption insurance deterioration in rural areas and, hence, the investments in children play the main role in that deterioration as per our results in Section 5.1.

The interesting scenario is that of urban areas, i.e., where the housing reform occurred. In urban areas, high housing-wealth households experience a clear loss of insurance against permanent risk between the pre-1997 years with a non-significant loading factor, $\psi_{\zeta}$, and the post-1997 years with a significant $\psi_{\zeta}$ of .3980 . This is definitely not the case for low housing-wealth households that show no significant change in their ability to insure against permanent risk over time. That is, housing wealth constitutes a reasonable argument behind the loss of insurance in urban areas attained in our benchmark results for urban areas. This argument does not apply to rural areas, where the housing reform did not occur.

The role of housing on consumption insurance has been recently emphasized in Kaplan et al. (2014). In the U.S. and other developed countries wealthy hand-to-mouth (HtM) households, those with a wealth portfolio largely based on housing, are less able to insure against transitory risk than wealthy households with a more liquid portfolio. Their reason to focus on transitory ("small") shocks is the notion that for permanent ("big") shocks wealthy HtM would actually sacrifice their housing wealth to insure their consumption. Our evidence does not support this idea for China. Chinese households are not willing to give up their housing wealth for better insurance against permanent shocks. This is perhaps not surprising for two reasons. First, the largely underdeveloped finance sector for households in China limits the availability to store wealth in liquid assets (Storesletten and Zilibotti, 2014), which makes Chinese households more likely to hold on to houses as almost the only effective form of storing wealth. ${ }^{49}$ Second, Chinese households have large incentives to invest in housing given the rise in the housing price after the

the value of residential units in all waves. For a discussion of data construction, see Appendix A.4.3. The home ownership in China is high, considering the U.S. home ownership rate of $65 \%$ in the fourth quarter of 2013 (see "Residential Vacancies and Homeownership in the Fourth Quarter 2013", U.S. Census Bureau News).

${ }^{49}$ That is, while savings constraints can be present in a development context (Dupas and Robinson, 2013; Kaboski et al., 2014; deMagalhaes and Santaeulàlia-Llopis, 2015), the high savings rates in China appears to suggest the absence of such constraints. However, the limitation to diversify a wealth portfolio can itself be considered as a saving constraint in growing economies with under-developed financial markets. 
housing reform (Wang, 2011) and the motivation for holding houses for its large returns in the marriage market (Wei and Zhang, 2011; Du and Wei, 2013). ${ }^{50}$

To summarize, a high savings rate does not necessarily indicate better insurance. One needs to look deeper at where the savings go in order to discuss consumption insurance. Our evidence suggests that in China, where the financial market is underdeveloped and households have limited options for storing wealth, the predominant life-cycle savings in the form of investments in children and housing are associated with the loss of consumption insurance against permanent income risk. Our results suggest that investments in children play an important role in both rural and urban areas. The role of housing wealth is restricted to urban areas, i.e., where the housing reform occurred.

\section{Welfare Effects of Growth, Risk and Insurance in China 1989-2009}

Since China is growing at the cost of higher risk and worse insurance, an accurate welfare assessment requires taking into account the welfare impacts of all three components, growth, risk and insurance. In this section, we first evaluate the welfare impact of these three components over the entire sample period separately in section 6.1. Then we examine what changes in these components from the 1990s to 2000s imply for changes in the welfare levels across time in section 6.2. Finally, we explore the spatial differences in growth, risk and insurance between rural and urban China, and assess the scope of welfare gains from migration in section 6.3.

To answer these questions, we compute consumption equivalent variations as in Lucas (1987). That is, we compute the percentage change in annual consumption $g$ across all periods and possible states of the world that a household in a reference environment $A$ requires to be exante indifferent between $A$ and a counterfactual environment $B$. The reference environment $A$ is defined by our estimates for the growth, $\gamma$, the amount of permanent and transitory risks, $\left\{\sigma_{\zeta}, \sigma_{\varepsilon}\right\}$, and the degree of partial insurance against the permanent and transitory risks, $\left\{\psi_{\zeta}, \psi_{\varepsilon}\right\}$. ${ }^{51}$ The alternative environment $B$ is then defined by the counterfactual in question, where one or more parameters of the environment, $\left\{\gamma, \sigma_{\zeta}, \sigma_{\varepsilon}, \psi_{\zeta}, \psi_{\varepsilon}\right\}$, are changed. We report results for three levels of risk aversion, $\eta=1,2,4$, all of which are standard in the literature. ${ }^{52}$

\footnotetext{
${ }^{50}$ See also Wang and Wen (2012) who examine the effect of rising housing prices on savings rates under a realistic mortgage down payment structure.

${ }^{51}$ For notational convenience, we drop the time subscript, but note that risk and insurance parameters are time-varying.

${ }^{52}$ The methodology of welfare assessments is standard and hence relegated to Appendix I.1. In brief, we start by computing from the initial income level and the household income growth rate an optimal deterministic consumption plan in a savings model. Then we simulate the partial insurance model to obtain fluctuations in consumption around the aforementioned deterministic consumption plan. The addition of the deterministic and the stochastic components is the final consumption path which we evaluate with a time-separable CRRA utility
} 


\subsection{The Welfare Effects of Growing with Risk}

What are the overall welfare impacts of growth, risk and insurance for rural and urban China? How do they compare to the U.S.? Here we evaluate the welfare gain from growth, the welfare cost of risk and of partial insurance for China, using the sample and estimates of our benchmark. We then conduct the same exercise for the U.S, using the sample and estimates from BPP.

The results are found in Table 7. In the first set of three columns in Table 7, the welfare gain from growth are expressed as the consumption reductions, in percentage terms, that make our households indifferent between their reference scenario with growth, $\left\{\gamma, \sigma_{\zeta}, \sigma_{\varepsilon}, \psi_{\zeta}, \psi_{\varepsilon}\right\}$, and the counterfactual with no growth, $\left\{0, \sigma_{\zeta}, \sigma_{\varepsilon}, \psi_{\zeta}, \psi_{\varepsilon}\right\}$. Removing an annual income growth of $4.8 \%$ in rural China amounts to a reduction of $37.77 \%$ of a rural resident's annual consumption, while removing an annual income growth of $5.7 \%$ in urban China amounts to a reduction of $43.42 \%$ of its annual consumption. In other words, income growth by itself brings about substantial improvements in welfare in China. This is independent of the degree of the risk aversion. For the U.S., the gain from growth is smaller at about $18.22 \%$ of annual consumption for a growth rate that is slightly under 3\% from 1978 to 1992.

In the second set of columns, we report the annual consumption variation that households growing with risk would need to be compensated with in order to be indifferent between their reference scenario and the counterfactual with no risk, $\left\{\gamma, 0,0, \psi_{\zeta}, \psi_{\varepsilon}\right\}$. This counterfactual describes an extreme stabilization policy that shuts down both the permanent and transitory risks. Alternatively, shutting down risk in this exercise is isomorphic to providing perfect insurance, i.e. $\left\{\gamma, \sigma_{\zeta}, \sigma_{\varepsilon}, 0,0\right\}$. Another way of interpreting the results is that they represent the welfare gain from completing markets. ${ }^{53}$ The welfare cost of risk or welfare gain from full insurance depends on the level of risk aversion. For $\eta=1$, the welfare cost of risk is $1.69 \%$ of annual consumption for rural China and 3.99\% for urban China, while this figure is 3.30\% for the U.S. For $\eta=2$, the magnitude of the welfare cost of risk increases by a factor of more than 2 to $4.06 \%$ and $8.94 \%$, respectively, for rural and urban China, and to $6.70 \%$ for the U.S. With $\eta=4$, one needs to increase the annual consumption by $14.58 \%$ and $27.68 \%$ in rural and urban China respectively to match the level of welfare without income risk. This figure is $15.99 \%$ for the U.S. ${ }^{54}$ In sum, the welfare cost of risk is twice as much in urban China as it is in rural China, and large in absolute

function. The ensuing experiments entail changing the income growth rate, the variances of the permanent or transitory income shocks or the risk transmission parameters in an alternative scenario, evaluating welfare under the alternative scenario and solving for consumption equivalent variations in the alternative which match the welfare level in the reference scenario.

${ }^{53}$ Note that in these two counterfactuals, the consumption is still random because of the taste shock.

${ }^{54}$ This nonlinearity of the consumption variation in the coefficient of risk aversion is also present in Storesletten et al. (2001). 
terms, accounting for roughly $1 / 7(2 / 7)$ of rural (urban) annual consumption.

Last, we ask how would an agent in the reference scenario assess living in a world with neither growth nor risks (or equivalently with no growth and perfect insurance), i.e., a stagnant life from cradle to grave. This corresponds to an extreme interpretation that all risks are generated by the growth process-i.e., giving up risks also implies giving up growth. The results are in the last set of columns of the same table. The welfare cost is $36.7 \%$ of their annual consumption for rural residents and $41.16 \%$ for urban residents with $\eta=1$. These costs decrease to $28.70 \%$ and $27.76 \%$ with $\eta=4$. Hence, conditional on the ability to insure, it is still the case that for the overall period of 1989 to 2009 Chinese households gain substantially from growing with risk, though the magnitude of the gain from growth per se can drop by as much as $24 \%$ for rural and by $36 \%$ for urban residents for $\eta=4$.

\subsection{Welfare Across Time: Pre- Versus Post-WTO}

The entrance to the WTO is associated with a process with faster growth as well as higher permanent risk and worse ability to insure for rural and urban Chinese households (see section 4.2). Here we quantify the cumulative effects of post-WTO growth, risk and insurance on welfare.

We start from the pre-WTO economic environment or the reference scenario defined by $\left\{\gamma^{\text {pre }}, \sigma^{\text {pre }}, \psi^{\text {pre }}\right\}$ and successively replace the growth rate, the variances of shocks and the insurance parameters with their post-WTO counterparts. ${ }^{55}$ We repeat this exercise for two initial conditions, $c_{0}^{\text {pre }}$ where we keep the initial consumption level in 1989 in the counterfactuals, and $c_{0}^{\text {post }}$ where we use the initial consumption level in 2000 in the counterfactuals. ${ }^{56}$ We also conduct this welfare exercise with two sets of data and estimates, one with the disposable income and the other with the earnings. The results are found in Table 8.

Focus on the results using disposable income in Table 8(a). First, replacing the pre-WTO growth rate of $4.43 \%(4.96 \%)$ for rural (urban) households with the post-WTO growth rate of $5.20 \%(6.71 \%)$, i.e. moving from $\left\{\gamma^{\text {pre }}, \sigma^{\text {pre }}, \psi^{\text {pre }}\right\}$ to $\left\{\gamma^{\text {post }}, \sigma^{\text {pre }}, \psi^{\text {pre }}\right\}$, certainly improves welfare, especially for urban households. It amounts to an increase of $4.37 \%$ of annual consumption in rural China and $10.31 \%$ of annual consumption in urban China from the reference scenario. A simultaneous increase in the initial consumption to the post-WTO level enhances these gains to $40.90 \%$ in rural and $50.02 \%$ in urban areas.

Second, when we introduce the post-WTO risk into the environment while keeping insurance

\footnotetext{
${ }^{55}$ We compactly write $\sigma=\left\{\sigma_{\zeta}, \sigma_{\varepsilon}\right\}$ and $\psi=\left\{\psi_{\zeta}, \psi_{\varepsilon}\right\}$. That is, we consider simultaneous changes in permanent and transitory components of risk and insurance.

${ }^{56}$ As is revealed in the data, $c_{0}^{\text {post }} / c_{0}^{\text {pre }}$ is 1.35 in rural areas and 1.36 in urban areas.
} 
at the pre-WTO level, i.e. $\left\{\gamma^{\text {post }}, \sigma^{\text {post }}, \psi^{\text {pre }}\right\}$, the picture then looks very different for rural and urban areas. In rural areas, the welfare gain from growing with risk is $3.16 \%$ of annual consumption in the reference scenario with $\eta=4$ and initial consumption at the 1989 level, which is just slightly lower than the $4.37 \%$ gain from growth without changing the risk factors. In contrast, growing with risk in urban areas entirely overturns the welfare gain from growth alone and imposes a cost of $6.57 \%$ of annual consumption. This welfare cost of growing with risk for the urban households is present for all levels of risk aversion with $c_{0}^{\text {pre }}$. Apart from the fact that the increase in risk is more pronounced from pre- to post-WTO period in urban areas than in rural areas, the urban residents are much less able to insure against the higher transitory risk with the pre-WTO insurance technology. ${ }^{57}$ This explains why the cost of introducing post-WTO risk is so much higher in urban areas.

Third, we now add the actual post-WTO insurance technology to our welfare analysis, $\left\{\gamma^{\text {post }}, \sigma^{\text {post }}, \psi^{\text {post }}\right\}$. We find sharp differences between rural and urban areas again. In urban areas, the improvement in the insurance against transitory risk more than offsets the loss in the insurance against permanent risk and substantially improves the welfare. With $\eta=4$, having the post-WTO level of insurance amounts to a $21.33 \%$ increase of annual consumption from the reference scenario for the urban residents. Instead, in rural areas, the worsening of the insurance against permanent risk in the post-WTO era implies a significant welfare loss of $9.05 \%$ of annual consumption for $\eta=4$. That is, the loss of insurance in rural areas is so large that it more than offsets any gain from post-WTO growth. In this case, rural households would prefer to live the growth-risk-insurance environment of the pre-WTO era. If we give them the initial level of consumption in 2000, then the welfare gain from adopting the post-WTO growth, risk and insurance becomes positive.

The welfare results from using the earnings measure, which are found in Table 8(b), are broadly consistent with the findings using the disposable income measure. It is noteworthy, however, that giving the urban households the post-WTO earnings growth, earnings risk and insurance implies a welfare loss of $4.28 \%$ when $\eta=4$ and initial consumption is at the 1989 level. In other words, once transfers are excluded, even the urban residents would prefer the growth-riskinsurance environment of the pre-WTO era. The insurance against transitory risk has improved in the post-WTO era with transfers, which is responsible for the positive gain observed with the disposable income measure.

The overall results are clear. First, post-WTO growth, risk and insurance implies a welfare

\footnotetext{
${ }^{57}$ Recall from section 4.2 , the transmission of the permanent risk is 0.1207 for the rural residents and 0.0772 for the urban residents, while the transmission of the transitory risk is effectively zero for the rural residents and 0.2111 for the urban residents.
} 
loss for rural households generated by the post-WTO worsening in the ability to insure against permanent risks that more than offsets the welfare gains from the post-WTO growth. Second, urban households also face welfare losses from post-WTO growth-risk-insurance environment when we exclude transfers, while the introduction of transfers largely increases their welfare.

\subsection{Welfare Across Space: Migrating from Rural to Urban Areas}

Here, we directly compare the welfare of rural and urban areas to explore the incentives of rural-tourban migration by embedding the rural households with, one by one, the properties of the urban households, i.e., consumption level, growth, risk and insurance. To explore how the evolution of public transfers-i.e., direct changes in social insurance-affects the incentive to migrate, we separately explore the welfare gains of migrating from rural to urban areas before and after China's entrance to WTO. As described in section 4.2, while rural and urban households share similar ability to insure against permanent income shocks, urban areas show a substantially worse ability to insure transitory shocks than rural areas for the years before 2000, although this is largely mitigated through the changes in the composition of public transfers in the 2000 s.

First, what are the welfare effects of urban growth on rural households? We define the reference environment by the estimates from the rural sample, i.e. $\left\{\gamma^{r}, \sigma^{r}, \psi^{r}\right\}$, against the counterfactual that introduces urban growth, i.e., $\left\{\gamma^{u}, \sigma^{r}, \psi^{r}\right\}$, and we do this separately for before and after WTO. Before WTO, rural disposable income growth is on average $4.43 \%$ and urban growth is $4.96 \%$. The welfare gains from urban growth on rural households is $2.98 \%$ of annual consumption under the initial level of rural consumption, $c_{0}^{r}$, see the first "Growth" column in panel (a.1) of Table 9. ${ }^{58}$ After WTO, rural growth is on average $5.20 \%$ and urban growth is $6.71 \%$, i.e., a larger rural-urban gap than before WTO, which implies larger welfare gains from urban growth on rural households, $6.24 \%$ of annual consumption under $c_{0}^{r}$, see the first "Growth" column in panel (a.2) of Table 9. Additionally providing rural households with the initial level of urban consumption, $c_{0}^{u}$, boosts the welfare gains to $9.68 \%$ before WTO and to $14.53 \%$ after WTO.

Second, what are the welfare effects of urban growth and risk on rural households? This is the case where rural households inherit not only urban growth but also its risk. That is, our counterfactual is now $\left\{\gamma^{u}, \sigma^{u}, \psi^{r}\right\}$. Urban permanent and transitory risks are both about $60 \%$ of those of rural areas (see section 4.2). If the rural insurance technology is preserved, then this decrease in risk associated with urban households should increase our counterfactual rural welfare.

\footnotetext{
${ }^{58}$ To isolate the effects of growth, risk and insurance from consumption-level effects, we conduct this exercise separately for the initial level in rural areas $c_{0}^{r}$ and the initial level in urban areas $c_{0}^{u}$ in 1989 , where $c_{0}^{u} / c_{0}^{r}=1.06$, as is revealed in the data.
} 
Indeed, ignoring level effects, rural households gain 3.28\% of annual consumption for $\eta=1$ and $4.00 \%$ for $\eta=4$ before WTO, see the first "Risk" column in panel (a.1) of Table 9, and 7.56\% of annual consumption for $\eta=1$ and $12.18 \%$ for $\eta=4$ after WTO, see the first "Risk" column in panel (a.2) of Table 9. Under $c_{0}^{u}$ these effects go up to $9.99 \%$ with $\eta=1$ and $10.76 \%$ with $\eta=4$ before WTO and $15.95 \%$ with $\eta=1$ and $20.93 \%$ with $\eta=4$ after WTO.

Third, what are the welfare effects of urban growth, risk and insurance on rural households? We now add the urban insurance technology to our counterfactual, i.e., $\left\{\gamma^{u}, \sigma^{u}, \psi^{u}\right\}$, see the results in the columns "Insurance Technology" in panel (a.1) and (a.2) in Table 9. Without level effects, i.e., under $c_{0}^{r}$, the loss in insurance against transitory shocks for rural households from embedding them with urban insurance technology implies that the welfare gains from urban growth and risk go down from 3.28\% with a 95\% confidence interval of $[3.21 \%, 3.35 \%]$ to $.93 \%$ with a $95 \%$ confidence interval of $[.53 \%, 1.34 \%]$ for $\eta=1$ and from $4.00 \%$ with a $95 \%$ confidence interval of $[3.63 \%, 4.41 \%]$ to $-3.13 \%$ with a $95 \%$ confidence interval of $[-5.81 \%,-0.51 \%]$ for $\eta=4$ before WTO. That is, the introduction of a much worse urban insurance technology (mainly against transitory shocks) on rural households entirely eliminates the welfare gains from migration in the years before WTO. If we consider that moving from rural to urban areas also implies an adjustment in the level of consumption of average urban consumption, $c_{0}^{u}$, then there are still welfare gains from migration but these gains drop by more than two-thirds from $10.76 \%$ with a $95 \%$ confidence interval of $[10.37 \%, 11.20 \%]$ to $3.16 \%$ with a $95 \%$ confidence interval of $[0.31 \%, 5.96 \%]$ due to the loss of consumption insurance associated with rural-to-urban migration.

In the years after WTO, urban insurance technology against transitory shocks improves approaching the degree of insurance in rural areas, mainly due to public transfers (see section 4.2). This improvement in urban insurance implies that the welfare gains from rural-to-urban migration after WTO increase with respect to the pre-WTO era. In the post-WTO era we find that the loss of consumption insurance from rural-to-urban migration implies that the welfare gains from migration barely drop from $15.95 \%$ to $13.33 \%$ with $\eta=1$ and from $20.93 \%$ to $19.05 \%$ with $\eta=$ 4 under $c_{0}^{u}$. Similar qualitative results are attained under $c_{0}^{r}$.

Finally, to explore the effects of public transfers on the incentives to migrate we compute the welfare gains under our measure of earnings. Focusing on capturing urban level effects under $c_{0}^{u}$, the welfare gains from the extra growth generated by moving a rural household to an urban area before WTO, i.e., $14.70 \%$, are larger than those attained with disposable income, see panel (b.1) in Table 9. This is explained by the larger gap of earnings growth between rural and urban households, $4.58 \%$ and $5.91 \%$ respectively, as compared to the gap of disposable income growth of $4.43 \%$ and $4.49 \%$. The further introduction of urban risk on rural households increases welfare gains to $16.68 \%$ and the introduction of urban insurance technology decreases these welfare 
gains to $15.86 \%$ if $\eta=4$. These changes are not significantly different from each other at a $95 \%$ confidence level. Similar qualitative results are attained after WTO with larger welfare gains, see panel (b.2) in Table 9.

To summarize, our results imply that the ability to insure consumption is quantitatively important for migration decisions and that this ability can be substantially affected by social insurance policy through public transfers. In the years before 2000, the worse ability to insure consumption in urban areas compared with rural areas significantly drops the welfare gains of rural-to-urban migration by $71 \%$ under $\eta=4$ and $c_{0}^{u}$. However, in the $2000 \mathrm{~s}$, improvements in the ability to insure transitory risk in urban areas (compared with rural areas) due to changes in the composition of public transfers imply that the welfare gains merely drop by a non-significant $8 \%$ after factoring in the loss in consumption insurance associated with that migration choice. ${ }^{59}$

\section{Policy Experiments: Tensions from Lower Economic Growth}

Specifically, we ask: what are the permissible levels of risks and insurance under a specific income growth rate for the period from 2011 to 2020 that keep the rural and urban residents as happy as in a world where the status quo persists? The status quo is our reference environment, i.e., our estimates of income growth (i.e., $\gamma$ ), risks (i.e., $\sigma_{\varepsilon}$ and $\sigma_{\zeta}$ ) and degree of consumption insurance (i.e., $\psi_{\varepsilon}$ and $\psi_{\zeta}$ ) of the period 2001 to 2009 in our sample. We consider two additional counterfactual growth scenarios: $\gamma$ less .50 percentage points, motivated by the widespread expectation that in the near term the GDP growth in China will drop, ${ }^{60}$ and $7.20 \%$, a rate that approximately delivers the medium-run objective of doubling the 2010 income by 2020 .

Our results are in Figure 5. In each panel, all pairs of the variance of income shocks (in percentage deviations from reference estimates, vertical axis) and the level of insurance (horizontal axis) preserve the same status-quo welfare. Then, each plotted curve shows the pairs that preserve this welfare for a specific growth scenario. First, note that these curves are downward sloping, which shows a negative trade-off between risk stabilization and social insurance policies in terms of preserving welfare. ${ }^{61}$ Second, the difference across curves shows the trade-off between growth

\footnotetext{
${ }^{59}$ Munshi and Rosenzweig (2016) finds that improvements in risk-sharing by $50 \%$ can double the migration rates in India. If we re-conduct our assessment on the welfare gains of migration simultaneously for our entire 1989-2009 sample as a whole, i.e., without exploring welfare separately for the pre- and post-WTO years, then we obtain that consumption insurance losses drop the welfare gains of rural-to-urban migration by about one-half, a similar figure to that in Morten (2013) for temporary migration in village India.

${ }^{60}$ According to the polling results of 50 economists in leading financial firms regarding the near-term economic outlook of China by Economic Consensus, the median of the projected GDP growth rate of China in 2015 is $7.00 \%$, which implies a .50\% decrease from the growth target set for 2014 .

${ }^{61}$ This is not necessarily the case for developed economies. For example, Krueger and Perri (2006) find that an increase in income inequality can increase welfare by decreasing the probability of default and hence increasing
} 
and risk and between growth and insurance. For example, a growth-enhancing reform that shifts curves to the right implies this economy tolerates more risk or requires less insurance to preserve welfare. That is, a right shift implies a positive trade-off between growth and risk and a negative trade-off between growth and insurance. Next, we explore these trade-offs quantitatively.

Let's focus first on permanent shocks in rural areas (see the top-left panel in Figure 5) and its reference environment, that is, the point in which the curve associated with reference growth $\gamma$-i.e., the black solid curve-crosses reference insurance (i.e., $\psi_{\zeta}=.2968$ ) and reference risk (i.e., where percentage deviations from $\sigma_{\zeta}$ are zero). Our results suggest that given $\gamma$, the rural economy would be able to sustain reference welfare with twice as much risk if social insurance policy improved the transmission of permanent income shocks to consumption to $\psi_{\zeta}=.2098$, i.e. by $1 / 3$ its reference value. Instead, if social insurance deteriorates and $\psi_{\zeta}$ increases by $1 / 3$ to .4 , the rural economy would require a risk stabilization policy that reduces the variance of income risks to $45 \%$ of its reference value in order to preserve welfare. Further, if growth reforms do not succeed and income grows at $\gamma$ minus .50\%-i.e., a shift to the left, the blue dashed curve - then, for the reference amount of risk, the rural areas would require an improvement in their social insurance policy that decreases $\psi_{\zeta}$ to .2891 , i.e., by $.2891 / .2968-1=-2.59 \%$. Or, alternatively, for the reference amount of insurance, the rural areas would require a successful risk stabilization policy that reduces permanent risk by $5.06 \%$. Instead, if growth-enhancing reforms succeed in achieving a rural annual growth rate of $7.2 \%$-i.e., a shift to the right, the red dotted curvethen, keeping the reference permanent risk, rural areas could tolerate a social insurance policy that increases $\psi_{\zeta}$ to .3255 , or keeping the reference amount of insurance, rural areas could tolerate a more relaxed risk stabilization policy that increases reference risk by $20.32 \%$. We also explore polices related to transitory risk (see the top-right panel in Figure 5). The level of insurance against transitory shocks is so high in rural areas that welfare is very inelastic with respect to risk: While keeping reference growth, transitory risk can double without having to further improve much the insurance parameter to preserve welfare. A successful growth-enhancing policy of $7.2 \%$ allows for a substantial worsening in insurance that increases $\psi_{\varepsilon}$ by a factor of 7 .

Finally, urban areas show a similar scenario in terms permanent risk to that of rural areas (see the bottom-right panel in Figure 5). Growing at $\gamma$ minus .50\% implies urban areas require, ceteris paribus, either an improvement in social insurance from .2200 to .2029 , i.e. by $-7.78 \%$, or alternatively, an increase in income stabilization to $-14.98 \%$ of reference permanent risk. Instead, a boost in growth to $7.2 \%$ implies that urban areas can tolerate a more relaxed social insurance policy that increases $\psi_{\zeta}$ to 2357 (if we were to keep the same amount of permanent risk), or

that amount of credit in equilibrium for the U.S. This suggests that the relationship between risk and insurance is likely to depend on the aggregate stage of economic development. 
a more relaxed risk stabilization policy that increases permanent risk by $14.82 \%$ of its reference value (if we were to keep the same amount of insurance). Similar to rural areas, we find transitory risk is more inelastic with respect to welfare, though somewhat less so in urban than in rural areas.

\section{Conclusion}

The process of economic growth is associated with a deterioration of consumption insurance. We obtain these results exploiting a rare opportunity to study the transmission of income inequality to consumption inequality for an economy that for a long period has experienced phenomenal growth and for which we can build a panel of household-level consumption and income, China 1989-2009. Our analysis show a clear deterioration of consumption insurance against permanent risks with a loading factor the triples during this period. We relate this insurance loss to two predominant life-cycle savings for Chinese households, i.e., investments in children and housing.

Our findings have important welfare implications for growth across time and space. First, rural households would prefer to live in the pre-WTO growth-risk-insurance environment rather than its post-WTO counterpart, maintaining the same initial condition, despite enjoying more growth in the post-WTO years. The reason is that in rural areas the welfare losses associated with the deterioration of insurance against permanent risk in the post-WTO years more than offset the welfare gains from post-WTO growth. Neither private nor public transfers help mitigate this insurance loss in rural areas. The case of urban households is different. We find urban households benefit from public transfers that substantially help them cope with the transmission of transitory risk to consumption after WTO. Indeed, without these public transfers, urban households would also choose the pre-WTO growth-risk-insurance environment. Second, although rural households would (on average) prefer to live in urban areas, the incentives to do so drop by more than twothirds in the pre-WTO years after factoring in the worse ability to insure consumption in urban areas compared with rural areas before the 2000s. However, as we show, the incentives to migrate can be substantially affected by social insurance policy. In particular, we find improvements in the ability to insure transitory risk in urban areas in the 2000s, due to changes in the composition of public transfers, that largely reduce the loss in consumption insurance associated with ruralto-urban migration.

Ultimately, our results suggest that there is value in assessing welfare across countries taking into account not only income per capita levels (or growth) but also individual risk and consumption insurance, and we call for such cross-country welfare evaluations. In doing so, it is natural to consider cross-country differences in the availability of consumption insurance mechanisms (e.g. self-insurance, limited commitment, limited information, etc.) and their degree of success within 
countries; see a first argument along these lines in Kocherlakota and Pistaferri (2008). As we have showed for China, this is particularly relevant for poor countries that start to take off from stagnation and that, hence, are potentially subject to large income shocks at the household level. Ours is not the first call for aggregate welfare measures that go beyond growth. Recently, Jones and Klenow (2016) have suggested welfare measures that include dimensions of economic inequality within countries. Instead, our exercise focuses on the penalization that the curvature of the utility function imposes on unanticipated changes in income that cannot be insured, hence smoothed. In this context, our study is more related to the work in Heathcote et al. $(2008,2014)$ in which insurance improvements also increase welfare for the U.S. However, in our framework, unlike in Heathcote et al. (2008, 2014), output (growth) is exogenously given and we simply detrend it as in Lucas (1987). This leads to our last statement.

As we look ahead, promising next frameworks are those where growth can be shaped by risk and insurance and vice versa, an argument that is not necessarily confined to China but extends to other developing countries. At present, the concepts of growth, risk and insurance are almost invariably studied in isolation with economic growth being usually explored at the aggregate/sectoral level (Herrendorf et al., 2014) while risk and insurance are usually explored at the household/family or village level (Karlan and Morduch, 2010). As per our findings on the last two decades of successful Chinese economic growth, we believe that shifting the current paradigm to unified frameworks that jointly determine growth, risk and insurance can be an important avenue for the positive and normative analysis of poor economies.

\section{References}

Aguiar, M. and Hurst, E. (2005). Consumption versus Expenditure. Journal of Political Economy, University of Chicago Press, 113(5):919-948.

Aguiar, M. and Hurst, E. (2014). Deconstructing Lifecycle Expenditures. Journal of Political Economy, University of Chicago Press. Forthcoming.

Aiyagari, S. R. (1994). Uninsured Idiosyncratic Risk and Aggregate Saving. The Quarterly Journal of Economics, 109(3):659-84.

Attanasio, O. and Davis, S. J. (1996). Relative Wage Movements and the Distribution of Consumption. Journal of Political Economy, 104(6):1227-62.

Attanasio, O., Hurst, E., and Pistaferri, L. (2014). The Evolution of Income, Consumption, and Leisure Inequality in the US, 1980-2010. In Improving the Measurement of Consumer Expenditures, NBER Chapters. National Bureau of Economic Research, Inc.

Bai, C.-E., Hsieh, C.-T., and Qian, Y. (2006). The Return to Capital in China. Brookings Papers on Economic Activity, 37:61-102. 
Banerjee, A., Meng, X., Porzio, T., and Qian, N. (2014). Aggregate Fertility and Household Savings: A General Equilibrium Analysis with Micro Data. NBER Working Paper.

Batis, C., Sotres-Alvarez, D., Gordon-Larsen, P., Mendez, M., and Popkin, B. M. (2014). Longitudinal Analysis of Dietary Patterns in Chinese Adults from 1991 to 2009. British Journal of Nutrition, 111(8):1441-51.

Beegle, K., DeWeerdt, J., Friedman, J., and Gibson, J. (2010). Methods of Household Consumption Measurement through Surveys: Experimental Results from Tanzania. Policy Research Working Paper, The World Bank.

Benjamin, D., Brandt, L., Giles, J., and Wang, S. (2008). Income Inequality During China's Economic Transition. In Brandt, L. and Rawski, T. G., editors, China's Great Economic Transformation, chapter 18. Cambridge University Press.

Bird, R. M. and Wong, C. P. W. (2005). China's Fiscal System: A Work in Progress. In Brandt, L. and Rawski, T. G., editors, China's Great Economic Transformation. Cambridge University Press.

Blundell, R., Pistaferri, L., and Preston, I. (2008). Consumption Inequality and Partial Insurance. American Economic Review, 98(5):1887-1927.

Bolt, J. and van Zanden, J. L. (2013). The First Update of the Maddison Project; Re-Estimating Growth Before 1820. Maddison Project, (4).

Bryan, G., Chowdhury, S., and Mobarak, A. M. (2014). Underinvestment in a Profitable Technology: The Case of Seasonal Migration in Bangladesh. Econometrica, 82:1671-1748.

Cai, H., Chen, Y., and an Zhou, L. (2010). Income and Consumption Inequality in Urban China: 1992-2003. Economic Development and Cultural Change, 58.

Carroll, C. D. (1997). Buffer-Stock Saving and the Life Cycle/Permanent Income Hypothesis. The Quarterly Journal of Economics, 112(1):1-55.

Carroll, C. D. and Kimball, M. S. (1996). On the Concavity of the Consumption Function. Econometrica, 64(4):981-92.

Carroll, C. D. and Kimball, M. S. (2001). Liquidity constraints and precautionary saving. Working Paper 8496, National Bureau of Economic Research.

Carroll, C. D., Parker, J. A., and Souleles, N. S. (2014). The Benefits of Panel Data in Consumer Expenditure Surveys. In Improving the Measurement of Consumer Expenditures, NBER Chapters. National Bureau of Economic Research, Inc.

Chamon, M., Liu, K., and Prasad, E. (2013). Income Uncertainty and Household Savings in China. Journal of Development Economics, 105:164177.

Cole, H. L., Greenwood, J., and Sanchez, J. M. (2016). Why doesn't technology flow from rich to poor countries? Econometrica, 84(4):1477-1521.

Deaton, A. (1991). Saving and Liquidity Constraints. Econometrica, 59(5):1221-48.

Deaton, A. (1997). The Analysis of Household Surveys: A Microeconometric Approach to Development Policy. The John Hopkins University Press. 
Deaton, A. and Zaidi, S. (2002). Guidelines for Constructing Consumption Aggregates for Welfare Analysis. Number 14101 in World Bank Publications. The World Bank.

deMagalhaes, L. and Santaeulàlia-Llopis, R. (2015). The Consumption, Income and Wealth of the Poorest: Cross-Sectional Facts of Rural and Urban Sub-Saharan Africa for Macroeconomists . Working paper, Bristol University and Washinton University in St. Louis.

Díaz-Giménez, J., Glover, A., and Ríos-Rull, J.-V. (2011). Facts on the Distributions of Earnings, Income, and Wealth in the United States: 2007 Update. Quarterly Review.

Dollar, D. and Wei, S.-J. (2007). Das (Wasted) Kapital: Firm Ownership and Investment Efficiency in China. NBER Working Paper No. 13103.

Du, Q. and Wei, S.-J. (2013). A Theory of the Competitive Saving Motive. Working Paper 18911, National Bureau of Economic Research.

Dupas, P. and Robinson, J. (2013). Why Don't the Poor Save More? Evidence from Health Savings Experiments. American Economic Review, 103(4):1138-71.

Fan, S., Kanbur, R., Wei, S.-J., and Zhang, X. (2013). The Economics of China: Successes and Challenges. Working Paper 19648, National Bureau of Economic Research.

Fang, H. (2014). Insurance Markets in China, chapter 44, pages 279-284. The Oxford Companion to the Economics of China. Oxford University Press.

Gollin, D., Parente, S. L., and Rogerson, R. (2002). The Role of Agriculture in Development. American Economic Review, 92(2):160-164.

Gollin, D., Parente, S. L., and Rogerson, R. (2004). Farm Work, Home Work, and International Productivity Differences. Review of Economic Dynamics, 7(4):827-850.

Greenwood, J. and Jovanovic, B. (1990). Financial Development, Growth, and the Distribution of Income. Journal of Political Economy, 98(5):1076-1107.

Greenwood, J., Sanchez, J. M., and Wang, C. (2010). Financing Development: The Role of Information Costs. American Economic Review, 100(4):1875-91.

Guvenen, F. (2007). Learning Your Earning: Are Labor Income Shocks Really Very Persistent? American Economic Review, 97(3):687-712.

Guvenen, F. and Smith, A. A. (2014). Inferring Labor Income Risk and Partial Insurance From Economic Choices. Econometrica, 82(6):2085-2129.

Harris, J. R. and Todaro, M. P. (1970). Migration, Unemployment and Development: A Two-Sector Analysis. American Economic Review, 60(1):126-142.

He, H., Huang, F., Liu, Z., and Zhu, D. (2013). Breaking the "Irong Rice Bowl" and Precautionary Savings: Evidence From Chinese State-Owned Enterprises Reform. Technical report. Working Paper, San Francisco FED.

Heathcote, J., Perri, F., and Violante, G. (2010a). Unequal We Stand: An Empirical Analsys of Economic Inequality in the United States, 1967-2006. Review of Economic Dynamics, 13(1):15-51. Special Issue, January 2010. 
Heathcote, J., Storesletten, K., and Violante, G. L. (2008). Insurance and Opportunities: A Welfare Analysis of Labor Market Risk. Journal of Monetary Economics, 55(3):501-525.

Heathcote, J., Storesletten, K., and Violante, G. L. (2009). Quantitative Macroeconomics with Heterogeneous Households. Annual Review of Economics, 1(1):319-354.

Heathcote, J., Storesletten, K., and Violante, G. L. (2010b). The Macroeconomic Implications of Rising Wage Inequality in the United States. Journal of Political Economy, 118(4):681-722.

Heathcote, J., Storesletten, K., and Violante, G. L. (2014). Consumption and labor supply with partial insurance: An analytical framework. American Economic Review, 104(7):2075-2126.

Herrendorf, B., Rogerson, R., and Valentinyi, k. (2014). Growth and Structural Transformation. In Handbook of Economic Growth, volume 2 of Handbook of Economic Growth, chapter 6, pages 855941. Elsevier.

Higgins, P., Zha, T., and Zhong, K. (2016). Forecasting China's Economic Growth and Inflation. Working Paper 22402, National Bureau of Economic Research.

Holmes, T. J., McGrattan, E. R., and Prescott, E. C. (2013). Quid Pro Quo: Technology Capital Transfers for Market Access in China. NBER Working Papers 19249, National Bureau of Economic Research, Inc.

Hsieh, C.-T. and Klenow, P. J. (2009). Misallocation and Manufacturing TFP in China and India. Quarterly Journal of Economics, 124:1403-1448.

Huang, J., Otsuka, K., and Rozelle, S. (2005). Agriculture in China's Development. In Brandt, L. and Rawski, T. G., editors, China's Great Economic Transformation. Cambridge University Press.

Huang, Y. (2008). Capitalism with Chinese Characteristics. Cambridge University Press.

Huggett, M. (1996). Wealth Distribution in Life-Cycle Economies. Journal of Monetary Economics, 38(3):469-494.

Jones, C. I. and Klenow, P. J. (2016). Beyond GDP? Welfare across Countries and Time. American Economic Review. Forthcoming.

Kaboski, J. P., Lipscomb, M., and Midrigan, V. (2014). The Aggregate Impact of Household Saving and Borrowing Constraints: Designing a Field Experiment in Uganda. American Economic Review, 104(5):171-76.

Kaplan, G. and Violante, G. L. (2010). How Much Consumption Insurance beyond Self-Insurance? American Economic Journal: Macroeconomics, 2(4):53-87.

Kaplan, G., Violante, G. L., and Weidner, J. (2014). The Wealthy Hand-to-Mouth. Brookings Papers on Economic Activity.

Karlan, D. and Morduch, J. (2010). Access to Finance, volume 5 of Handbook of Development Economics, chapter 71, pages 4703-4784. Elsevier.

Khan, A. R. and Riskin, C. (1998). Income and Inequality in China: Composition, Distribution and Growth of Household Income, 1988 to 1995. The China Quarterly, (154):221-253. 
Kimball, M. S. (1990). Precautionary Saving in the Small and in the Large. Econometrica, 58(1):53-73.

Kocherlakota, N. and Pistaferri, L. (2008). Inequality and Real Exchange Rates. Journal of the European Economic Association, 6(2-3):597-608.

Krueger, D. and Perri, F. (2006). Does Income Inequality Lead to Consumption Inequality? Evidence and Theory -super-1. Review of Economic Studies, 73(1):163-193.

Krusell, P. and Smith, A. A. (1998). Income and Wealth Heterogeneity in the Macroeconomy. Journal of Political Economy, 106(5):867-896.

Li, S., Chuliang, L., and Sicular, T. (2012). Overview: Income Inequality and Poverty in China, 20022007 . University of Western Ontario, CIBC Centre for Human Capital and Productivity Working Papers No. 201111.

Ligon, E. (2007). Risk and the Evolution of Inequality in China in an Era of Globalization. In Globalization and Poverty, NBER Chapters, pages 599-628. National Bureau of Economic Research, Inc.

Liu, J. and Li, S. (2011). Changes in Consumption Inequality in China. University of Western Ontario, CIBC Centre for Human Capital and Productivity Working Papers No. 201111.

Lucas, R. E. (1987). Models of Business Cycles. New York: Basil Blackwell, 1987.

Lucas, R. E. (2003). Macroeconomic Priorities. American Economic Review, 93(1):1-14.

Mace, B. J. (1991). Full Insurance in the Presence of Aggregate Uncertainty. Journal of Political Economy, 99(5):928-56.

Meng, X. (2003). Unemployment, Consumption Smoothing, and Precautionary Saving in Urban China. Journal of Comparative Economics, 31:465-485.

Modigliani, F. and Cao, S. L. (2004). The Chinese Saving Puzzle and the Life-Cycle Hypothesis. Journal of Economic Literature, XLII:145-170.

Morten, M. (2013). Temporary Migration and Endogenous Risk Sharing in Village India. Working Paper, Stanford University.

Munshi, K. and Rosenzweig, M. (2016). Networks and Misallocation: Insurance, Migration, and the Rural-Urban Wage Gap. American Economic Review, 106(1):46-98.

Nakamura, E., Steinsson, J., and Liu, M. (2016). Are chinese growth and inflation too smooth? evidence from engel curves. American Economic Journal: Macroeconomics, 8(3):113-44.

Oliveira, J. (2015). The value of children: Inter-generational support, fertility, and human capital. Journal of Development Economics.

Park, A. (2008). Rural-Urban Inequality in China. In Yusuf, S. and Nabeshima, K., editors, China Urbanizers: Consequences, Strategies, and Policies. Washington D.C.: The Work Bank.

Qian, N. (2009). Quantity-Quality and the One Child Policy:The Only-Child Disadvantage in School Enrollment in Rural China. Working Paper 14973, National Bureau of Economic Research. 
Ramey, G. and Ramey, V. A. (1995). Cross-Country Evidence on the Link between Volatility and Growth. American Economic Review, 85(5):1138-51.

Reenen, J. V. and Yueh, L. (2012). Why Has China Grown So Fast? The Role of International Technology Transfer. CEP Discussion Papers dp1121, Centre for Economic Performance, LSE.

Rios-Rull, J.-V. (1995). Models with Heterogeneous Agents. In Cooley, T. F., editor, Frontiers of Business Cycle Research. Princeton, NJ: Princeton Univ. Press.

Rosenzweig, M. and Zhang, J. (2014). Co-residence, life-cycle savings and inter-generational support in urban china. Working Paper 20057, National Bureau of Economic Research.

Rosenzweig, M. R. and Stark, O. (1989). Consumption Smoothing, Migration, and Marriage: Evidence from Rural India. Journal of Political Economy, 97(4):905-26.

Rosenzweig, M. R. and Zhang, J. (2009). Do Population Control Policies Induce More Human Capital Investment? Twins, Birth Weight and China's One-Child Policy. Review of Economic Studies, 76(3):1149-1174.

Song, Z., Storesletten, K., and Zilibotti, F. (2011). Growing Like China. American Economics Review, 101:196-233.

Storesletten, K., Telmer, C. I., and Yaron, A. (2001). The Welfare Cost of Business Cycles Revisited: Finite Lives and Cyclical Variation in Idiosyncratic Risk. European Economic Review, 45(7):13111339.

Storesletten, K. and Zilibotti, F. (2014). China's Great Convergence and Beyond. Annual Review of Economics.

Townsend, R. M. (1994). Risk and Insurance in Village India. Econometrica, 62(3):539-91.

Wang, S.-Y. (2011). State Misallocation and Housing Prices: Theory and Evidence from China. American Economic Review, 101:2081-2107.

Wang, X. and Wen, Y. (2012). Housing Prices and the High Chinese Saving Rate Puzzle. China Economic Review, 23:265-283.

Wei, S.-J. and Zhang, X. (2011). The Competitive Saving Motive: Evidence from Rising Sex Ratios and Savings Rates in China. Journal of Political Economy, 119(3):511 - 564.

Wu, X. and Perloff, J. M. (2004). China's Income Distribution and Inequality. Working Paper, University of Guelph and Berkeley University.

Yao, Y. (2014). The Chinese Growth Miracle. In Handbook of Economic Growth, volume 2 of Handbook of Economic Growth, chapter 7, pages 943-1031. Elsevier.

Yu, J. and Zhu, G. (2013). How Uncertain is Household Income in China? Economics Letters, 120(1):74-78.

Zhu, X. (2012). Understanding China's Growth: Past, Present, and Future. Journal of Economic Perspectives, 26(4):103. 
Table 1: Sample Characteristics: A Cross-Sectional Snapshot, CHNS 1989-2009

\begin{tabular}{|c|c|c|c|c|c|c|}
\hline & \multicolumn{3}{|c|}{1989} & \multicolumn{3}{|c|}{2009} \\
\hline & Total & Rural & Urban & Total & Rural & Urban \\
\hline Age & 42.0 & 40.6 & 44.8 & 49.0 & 49.0 & 49.2 \\
\hline \multicolumn{7}{|l|}{ Gender of Head(\%) } \\
\hline Male & 83.6 & 88.0 & 74.8 & 85.8 & 88.5 & 79.5 \\
\hline Female & 16.4 & 12.0 & 25.2 & 14.2 & 11.5 & 20.5 \\
\hline \multicolumn{7}{|c|}{ Education of Head (\%) } \\
\hline No schooling & 13.5 & 13.6 & 13.3 & 3.4 & 4.2 & 1.5 \\
\hline 1-9th Grade & 63.2 & 69.9 & 49.8 & 65.0 & 74.3 & 44.2 \\
\hline Above 9th Grade & 23.3 & 16.5 & 36.9 & 31.6 & 21.5 & 54.3 \\
\hline \multicolumn{7}{|l|}{ Household Structure } \\
\hline Household Size & 4.22 & 4.31 & 4.04 & 4.39 & 4.70 & 3.70 \\
\hline Weak DR & .48 & .55 & .35 & .14 & .15 & .11 \\
\hline Strong DR & .66 & .70 & .57 & .32 & .32 & .31 \\
\hline \multicolumn{7}{|l|}{ Province (\%) } \\
\hline Liaoning & 12.9 & 12.7 & 13.4 & 11.2 & 12.1 & 9.2 \\
\hline Heilongjiang & 0 & 0 & 0 & 11.2 & 10.6 & 12.5 \\
\hline Jiangsu & 11.6 & 11.9 & 11.1 & 11.0 & 11.3 & 10.4 \\
\hline Shandong & 11.8 & 11.8 & 11.8 & 10.2 & 10.0 & 10.6 \\
\hline Henan & 12.8 & 12.7 & 12.9 & 11.5 & 11.3 & 12.0 \\
\hline Hubei & 12.7 & 12.8 & 12.6 & 10.6 & 10.3 & 11.4 \\
\hline Hunan & 12.7 & 12.5 & 13.1 & 10.7 & 10.2 & 11.9 \\
\hline Guangxi & 12.9 & 13.0 & 12.7 & 12.1 & 12.6 & 11.0 \\
\hline Guizhou & 12.6 & 12.7 & 12.5 & 11.4 & 11.6 & 11.0 \\
\hline Num. Obs. & 3,331 & 2,227 & 1,104 & 3,665 & 2,542 & 1,123 \\
\hline
\end{tabular}

Notes: This table shows the summary statistics of the household head's demographic and education characteristics as well as the household structure in the level-trimmed CHNS sample of all households who satisfy the sample selection criteria (see section 3.1). 
Table 2: Income Partition by Rural and Urban Residency, China CHNS 1989 and 2009: Real 2009 USD

Year 1989

(a) Rural

\begin{tabular}{|c|c|c|c|c|c|c|c|c|c|c|c|c|}
\hline & \multicolumn{3}{|c|}{ Bottom(\%) } & \multicolumn{5}{|c|}{ Quintiles } & \multicolumn{3}{|c|}{ Top $(\%)$} & All \\
\hline & $0-1$ & $1-5$ & $5-10$ & $1 \mathrm{st}$ & 2nd & $3 r d$ & 4th & 5th & $10-5$ & $5-1$ & 1 & $0-100$ \\
\hline \multicolumn{13}{|c|}{ Averages, US\$ } \\
\hline Consumption & 397 & 375 & 397 & 391 & 400 & 424 & 439 & 491 & 479 & 522 & 516 & 430 \\
\hline Earnings & -13 & 38 & 71 & 80 & 205 & 336 & 497 & 897 & 897 & 1209 & 1829 & 413 \\
\hline Disp. Income & -5 & 41 & 83 & 95 & 227 & 370 & 568 & 1039 & 1015 & 1410 & 2042 & 459 \\
\hline \multicolumn{13}{|c|}{ Shares of Total $(\%)$} \\
\hline Consumption & .9 & 3.6 & 4.5 & 18.3 & 18.7 & 19.6 & 20.5 & 22.9 & 5.6 & 4.8 & 1.2 & 100 \\
\hline Earnings & .0 & .4 & .9 & 4.0 & 10.2 & 16.7 & 24.7 & 44.5 & 10.9 & 12.1 & 4.4 & 100 \\
\hline Disp. Income & .0 & .4 & .9 & 4.1 & 9.9 & 16.1 & 24.7 & 45.2 & 11.0 & 12.4 & 4.3 & 100 \\
\hline
\end{tabular}

e

Year 2009:

(a) Rural

\begin{tabular}{|c|c|c|c|c|c|c|c|c|c|c|c|c|}
\hline & \multicolumn{3}{|c|}{ Bottom(\%) } & \multicolumn{5}{|c|}{ Quintiles } & \multicolumn{3}{|c|}{ Тор(\%) } & All \\
\hline & $0-1$ & $1-5$ & $5-10$ & 1st & 2nd & $3 r d$ & 4th & 5th & $10-5$ & $5-1$ & 1 & $0-100$ \\
\hline \multicolumn{13}{|c|}{ Averages, US\$ } \\
\hline Consumption & 449 & 421 & 390 & 429 & 529 & 610 & 722 & 882 & 843 & 981 & 1060 & 637 \\
\hline Earnings & 2 & 20 & 57 & 100 & 368 & 712 & 1221 & 2709 & 2780 & 3609 & 6481 & 1076 \\
\hline Disp. Income & 11 & 43 & 99 & 138 & 434 & 794 & 1360 & 3122 & 3038 & 4414 & 7788 & 1169 \\
\hline \multicolumn{13}{|c|}{ Shares of Total (\%) } \\
\hline Consumption & .7 & 2.6 & 3.1 & 13.6 & 16.8 & 19.5 & 22.7 & 27.4 & 6.7 & 5.8 & 1.7 & 100 \\
\hline Earnings & .0 & .1 & .3 & 2.0 & 7.2 & 13.9 & 23.9 & 53.0 & 13.6 & 14.1 & 6.2 & 100 \\
\hline Disp. Income & .0 & .1 & .4 & 2.4 & 7.4 & 13.6 & 23.3 & 53.4 & 13.0 & 15.1 & 6.5 & 100 \\
\hline
\end{tabular}

(b) Urban

\begin{tabular}{|c|c|c|c|c|c|c|c|c|c|c|c|}
\hline \multicolumn{3}{|c|}{ Bottom(\%) } & \multicolumn{5}{|c|}{ Quintiles } & \multicolumn{3}{|c|}{ Top(\%) } & All \\
\hline $0-1$ & $1-5$ & $5-10$ & 1st & 2nd & $3 r d$ & 4 th & 5 th & $10-5$ & $5-1$ & 1 & $0-100$ \\
\hline \multicolumn{12}{|c|}{ Averages, US\$ } \\
\hline 441 & 406 & 363 & 397 & 417 & 471 & 491 & 528 & 528 & 444 & 507 & 458 \\
\hline-4 & 80 & 139 & 147 & 296 & 369 & 473 & 827 & 795 & 1131 & 1952 & 430 \\
\hline 59 & 144 & 231 & 245 & 443 & 575 & 743 & 1206 & 1199 & 1560 & 2393 & 642 \\
\hline \multicolumn{12}{|c|}{ Shares of Total (\%) } \\
\hline 1.0 & 3.6 & 3.7 & 16.9 & 18.3 & 20.7 & 21.4 & 22.7 & 5.6 & 3.8 & 1.1 & 100 \\
\hline .0 & .8 & 1.6 & 7.0 & 14.1 & 17.5 & 22.4 & 39.0 & 9.3 & 10.8 & 4.3 & 100 \\
\hline .1 & .9 & 1.8 & 7.7 & 13.8 & 17.9 & 23.2 & 37.4 & 9.3 & 9.8 & 3.5 & 100 \\
\hline
\end{tabular}

(b) Urban

\begin{tabular}{|c|c|c|c|c|c|c|c|c|c|c|c|}
\hline \multicolumn{3}{|c|}{ Bottom(\%) } & \multicolumn{5}{|c|}{ Quintiles } & \multicolumn{3}{|c|}{ Top $(\%)$} & All \\
\hline $0-1$ & $1-5$ & $5-10$ & 1st & 2nd & $3 r d$ & 4 th & 5th & $10-5$ & 5-1 & 1 & $0-100$ \\
\hline \multicolumn{12}{|c|}{ Averages, US\$ } \\
\hline 262 & 398 & 491 & 443 & 683 & 736 & 786 & 871 & 807 & 996 & 880 & 702 \\
\hline 1 & 24 & 156 & 194 & 621 & 1117 & 1776 & 2936 & 2822 & 3167 & 6341 & 1388 \\
\hline 23 & 87 & 256 & 333 & 907 & 1549 & 2385 & 4651 & 4496 & 6354 & 11489 & 1963 \\
\hline \multicolumn{12}{|c|}{ Shares of Total (\%) } \\
\hline .4 & 2.3 & 3.4 & 12.5 & 19.5 & 21.3 & 22.0 & 24.7 & 5.6 & 5.7 & 1.2 & 100 \\
\hline .0 & .0 & .6 & 2.9 & 9.3 & 16.9 & 26.7 & 44.1 & 10.6 & 9.7 & 4.5 & 100 \\
\hline .0 & .2 & .7 & 3.4 & 9.2 & 15.8 & 24.2 & 47.3 & 11.4 & 13.1 & 5.5 & 100 \\
\hline
\end{tabular}

Notes: This table shows the statistics of adult-equivalent household consumption, earnings (i.e., income without transfers) and disposable income, ranked by the adult-equivalent household disposable income, for rural and urban areas of China and for 1989 and 2009. The subtable titled "Averages, US" shows the average adult-equivalent household consumption, earnings and disposable income (in 2009 US dollars) for the range of the percentiles in the distribution of adult-equivalent household disposable income indicated by the header of the column. The subtable titled "Shares of Total (\%)" shows the percentage of the relevant consumption or income measure for a range of percentiles in the distribution of adult-equivalent household disposable income out of the simple aggregate of the consumption or income measure in the sample. For a discussion, see Section 3.2. 
Table 3: Minimum Distance Variance Estimates: Various Income Measures

\begin{tabular}{|c|c|c|c|c|c|c|c|c|c|}
\hline & & \multicolumn{2}{|c|}{$\begin{array}{l}\text { Disposable } \\
\text { Income }\end{array}$} & \multicolumn{2}{|c|}{$\begin{array}{c}\text { Earnings } \\
+ \text { Private Transf. }\end{array}$} & \multicolumn{2}{|c|}{$\begin{array}{c}\text { Earnings } \\
+ \text { Public Transf. }\end{array}$} & \multicolumn{2}{|c|}{ Earnings Only } \\
\hline & & Rural & Urban & Rural & Urban & Rural & Urban & Rural & Urban \\
\hline \multirow[t]{10}{*}{$\sigma_{\zeta}^{2}$} & $1992-3$ & .2238 & .0774 & .2668 & .1251 & .2091 & .0833 & .2608 & .0780 \\
\hline & & $(.0315)$ & $(.0293)$ & $(.0327)$ & $(.0324)$ & $(.0317)$ & $(.0296)$ & $(.0325)$ & $(.0272)$ \\
\hline & $1994-7$ & .2620 & .2456 & .2777 & .3331 & .2103 & .2610 & .2812 & .1616 \\
\hline & & $(.0529)$ & $(.0646)$ & $(.0535)$ & $(.0846)$ & $(.0498)$ & $(.0708)$ & $(.0521)$ & $(.0487)$ \\
\hline & 1998-00 & .2381 & .2055 & .2749 & .1944 & .2032 & .1859 & .2800 & .0723 \\
\hline & & $(.0525)$ & $(.0701)$ & $(.0553)$ & $(.0821)$ & $(.0520)$ & $(.0857)$ & $(.0525)$ & $(.0508)$ \\
\hline & 2001-4 & .3762 & .2501 & .4200 & .6870 & .3881 & .3565 & .4027 & .2063 \\
\hline & & $(.0549)$ & $(.0614)$ & $(.0585)$ & $(.1151)$ & $(.0494)$ & $(.0807)$ & $(.0483)$ & $(.0550)$ \\
\hline & $2005-6$ & .3160 & .2432 & .3810 & .5521 & .2718 & .1235 & .2391 & .1316 \\
\hline & & $(.0403)$ & $(.0452)$ & $(.0399)$ & $(.0766)$ & $(.0354)$ & $(.0393)$ & $(.0353)$ & $(.0438)$ \\
\hline$\sigma_{\zeta, p r e 97}^{2}$ & (ann.) & .0913 & .0488 & .1050 & .0718 & .0814 & .0521 & .1037 & .0396 \\
\hline$\sigma_{\zeta, p o s t 97}^{2}$ & (ann.) & 1170 & .0887 & .1373 & .1888 & 1059 & .0709 & 1067 & .0506 \\
\hline \multirow[t]{12}{*}{$\sigma_{\varepsilon}^{2}$} & 1991 & .2835 & .1267 & .2922 & .1427 & .2870 & .1309 & .2998 & .1520 \\
\hline & & $(.0193)$ & $(.0164)$ & $(.0201)$ & $(.0197)$ & $(.0197)$ & $(.0166)$ & $(.0200)$ & $(.0178)$ \\
\hline & 1993 & .3874 & .2581 & .3511 & .2103 & .3974 & .2564 & .3544 & .1981 \\
\hline & & $(.0320)$ & $(.0302)$ & $(.0324)$ & $(.0332)$ & $(.0323)$ & $(.0310)$ & $(.0326)$ & $(.0276)$ \\
\hline & 1997 & .4626 & .2258 & .4774 & .3300 & .4578 & .2171 & .4652 & .2094 \\
\hline & & $(.0435)$ & $(.0503)$ & $(.0447)$ & $(.0713)$ & $(.0425)$ & $(.0557)$ & $(.0418)$ & $(.0475)$ \\
\hline & 2000 & .5274 & .3062 & .5177 & .3157 & .4758 & .3683 & .3829 & .2788 \\
\hline & & $(.0460)$ & $(.0511)$ & $(.0465)$ & $(.0546)$ & $(.0431)$ & $(.0580)$ & $(.0355)$ & $(.0493)$ \\
\hline & 2004 & .4660 & .3024 & .4160 & .2652 & 3993 & .3241 & .4037 & .2721 \\
\hline & & $(.0352)$ & $(.0422)$ & $(.0342)$ & $(.0541)$ & $(.0337)$ & $(.0416)$ & $(.0329)$ & $(.0389)$ \\
\hline & 2006 & .3917 & 2219 & .3658 & 2478 & .3800 & .2576 & .3795 & .2412 \\
\hline & & $(.0318)$ & $(.0369)$ & $(.0311)$ & $(.0511)$ & $(.0287)$ & $(.0337)$ & $(.0308)$ & $(.0426)$ \\
\hline$\sigma_{\varepsilon, p r e 97}^{2}$ & (ann.) & .3862 & .1999 & .3876 & .2410 & .3875 & .1971 & .3854 & .1878 \\
\hline$\sigma_{\varepsilon, p o s t 97}^{2}$ & (ann.) & .4504 & .2704 & .4205 & .2710 & .4103 & .3076 & .3884 & .2608 \\
\hline Num. Obs & & 3,560 & 1,825 & 3,559 & 1,820 & 3,549 & 1,820 & 3,546 & 1,814 \\
\hline
\end{tabular}

Notes: This table shows the estimation results from a partial insurance model where different measures of income are used, for rural and urban areas separately. The $\sigma_{\zeta}^{2}$ refers to the sum of the variances of permanent shocks over the period specified in the second column of the table. The $\sigma_{\varepsilon}^{2}$ refers to the variance of transitory shocks in the year specified in the second column. We also provide the annualized variance of permanent (transitory) shocks over the pre-1997 period, $\sigma_{\zeta, \text { pre } 97}^{2}\left(\sigma_{\varepsilon, \text { pre } 97}^{2}\right)$, and that over the post-1997 period, $\sigma_{\zeta, \text { post } 97}^{2}\left(\sigma_{\varepsilon, \text { post97 }}^{2}\right)$. Asymptotic standard errors are in the parentheses. For a discussion of the model set-up see section 4.1 and of the results see section 4.2 . 
Table 4: Minimum Distance Partial Insurance Estimates: Various Income Measures

\begin{tabular}{|c|c|c|c|c|c|c|c|c|c|}
\hline & & \multicolumn{2}{|c|}{$\begin{array}{l}\text { Disposable } \\
\text { Income }\end{array}$} & \multicolumn{2}{|c|}{$\begin{array}{c}\text { Earnings } \\
+ \text { Private Transf. }\end{array}$} & \multicolumn{2}{|c|}{$\begin{array}{c}\text { Earnings } \\
+ \text { Public Transf. }\end{array}$} & \multicolumn{2}{|c|}{ Earnings Only } \\
\hline & & Rural & Urban & Rural & Urban & Rural & Urban & Rural & Urban \\
\hline \multicolumn{2}{|l|}{$\psi_{\zeta, p r e 97}$} & $\begin{array}{l}.1207 \\
(.0437)\end{array}$ & $\begin{array}{l}.0766 \\
(.0949)\end{array}$ & $\begin{array}{l}.0825 \\
(.0392)\end{array}$ & $\begin{array}{l}.1219 \\
(.0765)\end{array}$ & $\begin{array}{l}.1397 \\
(.0486)\end{array}$ & $\begin{array}{l}.1287 \\
(.0926)\end{array}$ & $\begin{array}{l}.1082 \\
(.0385)\end{array}$ & $\begin{array}{l}.2038 \\
(.1195)\end{array}$ \\
\hline \multicolumn{2}{|l|}{$\psi_{\zeta, p o s t 97}$} & $\begin{array}{l}.2968 \\
(.0320)\end{array}$ & $\begin{array}{l}.2200 \\
(.0542)\end{array}$ & $\begin{array}{l}.2703 \\
(.0273)\end{array}$ & $\begin{array}{l}.0704 \\
(.0320)\end{array}$ & $\begin{array}{l}.3059 \\
(.0345)\end{array}$ & $\begin{array}{l}.1530 \\
(.0632)\end{array}$ & $\begin{array}{l}.2796 \\
(.0358)\end{array}$ & $\begin{array}{l}.1788 \\
(.0990)\end{array}$ \\
\hline \multicolumn{2}{|l|}{$\psi_{\varepsilon, p r e 97}$} & $\begin{array}{l}-.0242 \\
(.0291)\end{array}$ & $\begin{array}{l}.2116 \\
(.0526)\end{array}$ & $\begin{array}{l}-.0170 \\
(.0302)\end{array}$ & $\begin{array}{l}.0829 \\
(.0694)\end{array}$ & $\begin{array}{l}-.0164 \\
(.0288)\end{array}$ & $\begin{array}{l}.1721 \\
(.0581)\end{array}$ & $\begin{array}{l}-.0226 \\
(.0290)\end{array}$ & $\begin{array}{l}.0750 \\
(.0727)\end{array}$ \\
\hline \multicolumn{2}{|l|}{$\psi_{\varepsilon, p o s t 97}$} & $\begin{array}{l}.0062 \\
(.0277)\end{array}$ & $\begin{array}{l}.0608 \\
(.0588)\end{array}$ & $\begin{array}{l}-.0160 \\
(.0287)\end{array}$ & $\begin{array}{l}.1131 \\
(.0596)\end{array}$ & $\begin{array}{l}.0231 \\
(.0300)\end{array}$ & $\begin{array}{l}.0832 \\
(.0498)\end{array}$ & $\begin{array}{l}.0188 \\
(.0331)\end{array}$ & $\begin{array}{l}.1162 \\
(.0542)\end{array}$ \\
\hline \multicolumn{2}{|l|}{$\sigma_{\xi}^{2}$} & .0191 & .0162 & .0196 & .0196 & .0189 & .0177 & .0197 & .0192 \\
\hline \multirow[t]{11}{*}{$\sigma_{u^{c}}^{2}$} & 1991 & .1219 & .1320 & .1221 & .1329 & .1218 & .1320 & .1215 & .1327 \\
\hline & 1993 & $\begin{array}{l}(.0050) \\
.1291\end{array}$ & $\begin{array}{l}(.0079) \\
.0947\end{array}$ & $\begin{array}{l}(.0049) \\
.1294\end{array}$ & $\begin{array}{l}(.0082) \\
.1029\end{array}$ & $\begin{array}{l}(.0050) \\
.1291\end{array}$ & $\begin{array}{l}(.0079) \\
.0976\end{array}$ & $\begin{array}{l}(.0049) \\
.1287\end{array}$ & $\begin{array}{l}(.0081) \\
.1035\end{array}$ \\
\hline & & $(.0087)$ & $(.0136)$ & $(.0086)$ & $(.0138)$ & $(.0086)$ & $(.0137)$ & $(.0086)$ & $(.0136)$ \\
\hline & 1997 & .1680 & .1569 & .1678 & .1579 & .1691 & .1578 & .1669 & .1597 \\
\hline & & $(.0123)$ & $(.0197)$ & $(.0123)$ & (.0197) & $(.0123)$ & $(.0197)$ & $(.0123)$ & $(.0198)$ \\
\hline & 2000 & .2091 & .1611 & .2088 & .1537 & .2086 & .1577 & .2076 & .1527 \\
\hline & & $(.0133)$ & $(.0188)$ & $(.0133)$ & $(.0187)$ & $(.0132)$ & $(.0185)$ & $(.0133)$ & $(.0180)$ \\
\hline & 2004 & .1882 & .1601 & .1881 & .1574 & .1878 & .1593 & .1892 & .1567 \\
\hline & & $(.0118)$ & $(.0180)$ & $(.0118)$ & $(.0179)$ & $(.0118)$ & $(.0180)$ & $(.0118)$ & $(.0178)$ \\
\hline & 2006 & .1897 & .1839 & .1889 & .1828 & .1913 & .1865 & .1943 & .1824 \\
\hline & & $(.0087)$ & $(.0140)$ & $(.0087)$ & $(.0136)$ & $(.0085)$ & $(.0138)$ & $(.0085)$ & $(.0136)$ \\
\hline Num. Obs & & 3,560 & 1,825 & 3,559 & 1,820 & 3,549 & 1,820 & 3,546 & 1,814 \\
\hline
\end{tabular}

Notes: This table shows the estimation results from a partial insurance model where different measures of income are used, for rural and urban areas separately. We allow the insurance parameters $\psi_{\zeta}$ (against permanent income shocks) and $\psi_{\varepsilon}$ (against transitory shocks) to vary from before to after 1997. $\sigma_{\xi}^{2}$ is the variance of the taste shock and $\sigma_{u^{c}}^{2}$ is the time-varying variance of the measurement error in consumption. Asymptotic standard errors are in the parentheses. For a discussion of the model set-up see section 4.1 and of the results see section 4.2. 
Table 5: Minimum Distance Partial Insurance Estimates: By Investments in Children

\begin{tabular}{l|cccc}
\hline \hline & \multicolumn{2}{c}{ Rural } & \multicolumn{2}{c}{ Urban } \\
\hline Inv. in Children: & Low & High & Low & High \\
\hline \multirow{2}{*}{$\psi_{\zeta, \text { pre } 97}$} & .0991 & .1331 & .2217 & -.0998 \\
& $(.3085)$ & $(.1455)$ & $(.2835)$ & $(.1241)$ \\
$\psi_{\zeta, \text { post } 97}$ & .1713 & .5260 & .0639 & .5124 \\
& $(.0686)$ & $(.1012)$ & $(.0581)$ & $(.1383)$ \\
Num. Obs. & 589 & 319 & 242 & 171 \\
\hline \hline
\end{tabular}

Notes: The partition criterion is based on below (for low) and above (for high) median values of the ratio of the expenditure on child education to the household saving in 2006. Our measure of income is our benchmark disposable income. The parameters $\psi_{\zeta, \text { pre } 97}$ and $\psi_{\zeta, \text { post } 97}$ refer to insurance (loading factors) against permanent shocks in the pre-1997 period and the post-1997 period. Asymptotic standard errors are in the parentheses. For a discussion of the results of this Table see section 5. For brevity, only insurance parameters are reported. 
Table 6: Minimum Distance Partial Insurance Estimates: By Housing Wealth

\begin{tabular}{c|cccc}
\hline \hline & \multicolumn{2}{c}{ Rural } & \multicolumn{2}{c}{ Urban } \\
\hline Housing Wealth: & Low & High & Low & High \\
\hline \multirow{2}{*}{$\psi_{\zeta, \text { pre } 97}$} & .1213 & .1373 & .0850 & -.0898 \\
& $(.0611)$ & $(.0671)$ & $(.1116)$ & $(.2037)$ \\
$\psi_{\zeta, \text { post97 }}$ & .3071 & .3313 & .0837 & .3980 \\
& $(.0473)$ & $(.0501)$ & $(.0671)$ & $(.0932)$ \\
Num. Obs. & 1,604 & 1,580 & 636 & 628 \\
\hline \hline
\end{tabular}

Notes: The partition criterion is based on below (for low) and above (for high) median values of housing wealth. Our measure of income is our benchmark disposable income. The parameters $\psi_{\zeta, \text { pre } 97}$ and $\psi_{\zeta, \text { post } 97}$ refer to insurance (loading factors) against permanent shocks in the pre-1997 period and the post-1997 period. Asymptotic standard errors are in the parentheses. For a discussion of the results of this Table see section 5. For brevity, only insurance parameters are reported. 
Table 7: Welfare Effects of Growing with Risk, China and U.S.

\begin{tabular}{|c|c|c|c|c|c|c|c|c|c|}
\hline \multirow[b]{2}{*}{ CRRA } & \multicolumn{3}{|c|}{$\begin{array}{c}\text { No Growth } \\
\left\{0, \sigma_{\zeta}, \sigma_{\varepsilon}, \psi_{\zeta}, \psi_{\varepsilon}\right\}\end{array}$} & \multicolumn{3}{|c|}{$\begin{array}{c}\text { No Risk } \\
\left\{\gamma, 0,0, \psi_{\zeta}, \psi_{\varepsilon}\right\}\end{array}$} & \multicolumn{3}{|c|}{$\begin{array}{c}\text { No Growth \& No Risk } \\
\left\{0,0,0, \psi_{\zeta}, \psi_{\varepsilon}\right\}\end{array}$} \\
\hline & Rural & Urban & U.S. & Rural & Urban & U.S. & Rural & Urban & U.S. \\
\hline$\eta=1$ & $-37.77 \%$ & $-43.42 \%$ & $-18.22 \%$ & $1.69 \%$ & $3.99 \%$ & $3.30 \%$ & $-36.72 \%$ & $-41.16 \%$ & $-15.52 \%$ \\
\hline$\eta=2$ & $-37.77 \%$ & $-43.42 \%$ & $-18.22 \%$ & $4.06 \%$ & $8.94 \%$ & $6.70 \%$ & $-35.25 \%$ & $-38.36 \%$ & $-12.74 \%$ \\
\hline$\eta=4$ & $-37.77 \%$ & $-43.42 \%$ & $-18.22 \%$ & $14.58 \%$ & $27.68 \%$ & $15.99 \%$ & $-28.70 \%$ & $-27.76 \%$ & $-5.15 \%$ \\
\hline
\end{tabular}

Notes: The reference scenario is defined by the actual estimates of growth, risk and insurance parameters, i.e., $\left\{\gamma, \sigma_{\zeta}, \sigma_{\varepsilon}, \psi_{\zeta}, \psi_{\varepsilon}\right\}$, separately for rural and urban China in section 4.2. The values in this table are consumption compensations for variations in growth and/or risk, see section 6 for a discussion. A positive value indicates a welfare gain of moving to the alternative scenario, that is, the amount of consumption (in units of percentage) across all periods and states that individuals living in our reference scenario will demand to remain indifferent between their current scenario and the alternative counterfactual scenario. We consider three alternative combinations of growth and risks scenarios as counterfactuals: Not growing with risks, growing without risk, and the case of no growth and no risks. For the case of the U.S. we use the benchmark estimates reported in Blundell et al. (2008), i.e., the before-tax earnings as is in the case of earnings only in their Table 7; only male earnings net of own taxes is available. For the U.S. we use an average growth rate of real personal income of $2.87 \%$, and of real personal disposable income of $2.96 \%$ for the period $1979-1992$ - these figures are computed using the nominal values from personal income and personal disposable income from NIPA-Table 2.1 deflated with the price index for personal consumption expenditures from NIPA-Table 2.3.4. For the case of China, we conduct this exercise separately for rural and urban households. All our results are significantly different from zero at $95 \%$ confidence levels. 
Table 8: Welfare Effects of Growth, Risk and Insurance Across Time: Pre-WTO to Post-WTO

(a) Disposable Income

(a.1) Rural

\begin{tabular}{|c|c|c|c|c|c|c|}
\hline & \multicolumn{6}{|c|}{ Cumulative Effect: Pre-WTO (pre) to Post-WTO (post) } \\
\hline \multirow[t]{2}{*}{ CRRA: } & \multicolumn{2}{|c|}{$\begin{array}{c}\text { Growth } \\
\left\{\gamma^{\text {post }}, \sigma^{\text {pre }}, \psi^{\text {pre }}\right\}\end{array}$} & \multicolumn{2}{|c|}{$\begin{array}{c}\text { Risk } \\
\left\{\gamma^{\text {post }}, \sigma^{\text {post }}, \psi^{\text {pre }}\right\}\end{array}$} & \multicolumn{2}{|c|}{$\begin{array}{c}\text { Insurance Tech. } \\
\left\{\gamma^{\text {post }}, \sigma^{\text {post }}, \psi^{\text {post }}\right\}\end{array}$} \\
\hline & $c_{0}^{p r e}$ & $c_{0}^{\text {post }}$ & $c_{0}^{\text {pre }}$ & $c_{0}^{p o s}$ & $c_{0}^{\text {pre }}$ & $c_{0}^{\text {post }}$ \\
\hline$\eta=1$ & $4.37 \%$ & $40.90 \%$ & $4.20 \%$ & $40.68 \%$ & $1.25 \%$ & $36.68 \%$ \\
\hline$\eta=2$ & $4.37 \%$ & $40.90 \%$ & $3.95 \%$ & $40.34 \%$ & $-2.12 \%$ & $32.14 \%$ \\
\hline$\eta=4$ & $4.37 \%$ & $40.90 \%$ & $3.16 \%$ & $39.27 \%$ & $-9.05 \%$ & $22.79 \%$ \\
\hline
\end{tabular}

(a.2) Urban

\begin{tabular}{c|c|c|c|}
\hline & \multicolumn{4}{|c|}{ Cumulative Effect: Pre-WTO $($ pre $)$ to Post-WTO $($ post $)$} \\
\hline \multirow{2}{*}{ CRRA: } & Growth & Risk & Insurance Tech. \\
& $\left\{\gamma^{\text {post }}, \sigma^{\text {pre }}, \psi^{\text {pre }}\right\}$ & $\left\{\gamma^{\text {post }}, \sigma^{\text {post }}, \psi^{\text {pre }}\right\}$ & $\left\{\gamma^{\text {post }}, \sigma^{\text {post }}, \psi^{\text {post }}\right\}$ \\
\hline & $c_{0}^{\text {pre }} \quad c_{0}^{\text {post }}$ & $c_{0}^{\text {pre }} c_{0}^{\text {post }}$ & $c_{0}^{\text {pre }} \quad c_{0}^{\text {post }}$ \\
\hline
\end{tabular}

$\eta=1 \quad 10.31 \% \quad 50.02 \% \quad-19.65 \% \quad 9.28 \% \quad 11.42 \% \quad 51.53 \%$

$\eta=2 \quad 10.31 \% \quad 50.02 \% \quad-15.34 \% \quad 15.13 \% \quad 12.62 \% \quad 53.16 \%$

\begin{tabular}{lllllll}
$\eta=4$ & $10.31 \%$ & $50.02 \%$ & $-6.57 \%$ & $27.06 \%$ & $21.33 \%$ & $65.01 \%$ \\
\hline
\end{tabular} (b) Earnings

(b.1) Rural

\begin{tabular}{|c|c|c|c|c|c|c|}
\hline & \multicolumn{6}{|c|}{ Cumulative Effect: Pre-WTO (pre) to Post-WTO (post) } \\
\hline CRRA & \multicolumn{2}{|c|}{$\begin{array}{c}\text { Growth } \\
\left\{\gamma^{\text {post }}, \sigma^{\text {pre }}, \psi^{\text {pre }}\right\}\end{array}$} & \multicolumn{2}{|c|}{$\begin{array}{c}\text { Risk } \\
\left\{\gamma^{\text {post }}, \sigma^{\text {post }}, \psi^{\text {pre }}\right\}\end{array}$} & \multicolumn{2}{|c|}{$\begin{array}{c}\text { Insurance Tech. } \\
\left\{\gamma^{\text {post }}, \sigma^{\text {post }}, \psi^{\text {post }}\right\}\end{array}$} \\
\hline & $c_{0}^{p r e}$ & $c_{0}^{\text {post }}$ & $c_{0}^{p r e}$ & $c_{0}^{\text {post }}$ & $c_{0}^{p r e}$ & $c_{0}^{\text {post }}$ \\
\hline$\eta=1$ & $4.03 \%$ & $40.43 \%$ & $4.06 \%$ & $40.48 \%$ & $1.71 \%$ & $37.31 \%$ \\
\hline$\eta=2$ & $4.03 \%$ & $40.43 \%$ & $4.04 \%$ & $40.46 \%$ & $-0.74 \%$ & $34.00 \%$ \\
\hline$\eta=4$ & $4.03 \%$ & $40.43 \%$ & $3.88 \%$ & $40.23 \%$ & $-5.20 \%$ & $27.99 \%$ \\
\hline
\end{tabular}

(b.2) Urban

\begin{tabular}{|c|c|c|c|c|c|c|}
\hline & \multicolumn{6}{|c|}{ Cumulative Effect: Pre-WTO (pre) to Post-WTO (post) } \\
\hline CRRA: & \multicolumn{2}{|c|}{$\begin{array}{c}\text { Growth } \\
\left\{\gamma^{\text {post }}, \sigma^{\text {pre }}, \psi^{\text {pre }}\right\}\end{array}$} & \multicolumn{2}{|c|}{$\begin{array}{c}\text { Risk } \\
\left\{\gamma^{\text {post }}, \sigma^{\text {post }}, \psi^{\text {pre }}\right\}\end{array}$} & \multicolumn{2}{|c|}{$\begin{array}{c}\text { Insurance Tech. } \\
\left\{\gamma^{\text {post }}, \sigma^{\text {post }}, \psi^{\text {post }}\right\}\end{array}$} \\
\hline & $c_{0}^{\text {pre }}$ & $c_{0}^{\text {post }}$ & $c_{0}^{\text {pre }}$ & $c_{0}^{\text {post }}$ & $c_{0}^{\text {pre }}$ & $c_{0}^{\text {post }}$ \\
\hline$\eta=1$ & $1.53 \%$ & $38.08 \%$ & $-24.57 \%$ & $2.59 \%$ & $0.58 \%$ & $36.78 \%$ \\
\hline$\eta=2$ & $1.53 \%$ & $38.08 \%$ & $-19.70 \%$ & $9.20 \%$ & $-0.57 \%$ & $35.23 \%$ \\
\hline$\eta=4$ & $1.53 \%$ & $38.08 \%$ & $-12.15 \%$ & $19.48 \%$ & $-4.28 \%$ & $30.18 \%$ \\
\hline
\end{tabular}

Notes: We take as reference scenario the actual estimates of growth, risk and insurance in the pre-WTO period reported in section 4.2 . We do this separately for two measures of household income, disposable income in panel (a) and earnings in panel (b). The columns headed with $c_{0}^{p r e}$ refer to the case where we keep the initial level of consumption in 1989 in the counterfactual environment, while the columns headed with $c_{0}^{\text {post }}$ refer to the case where we replace the initial level of consumption in 1989 for the initial level of consumption in 2000 in the counterfactual environment. 
Table 9: Welfare Effects of Growth, Risk and Insurance Across Space: Rural to Urban

(a) Disposable Income

(a.1) Pre-WTO

\begin{tabular}{c|cc|cccc|}
\hline & \multicolumn{6}{|c|}{ Cumulative Effect: Rural $(r)$ to Urban $(u)$} \\
\hline CRRA: & $\begin{array}{c}\text { Growth } \\
\left\{\gamma^{u}, \sigma^{r}, \psi^{r}\right\}\end{array}$ & \multicolumn{2}{c}{$\begin{array}{c}\text { Risk } \\
\left\{\gamma^{u}, \sigma^{u}, \psi^{r}\right\}\end{array}$} & $\begin{array}{c}\text { Insurance Tech. } \\
\left\{\gamma^{u}, \sigma^{u}, \psi^{u}\right\}\end{array}$ \\
\hline & $c_{0}^{r}$ & $c_{0}^{u}$ & $c_{0}^{r}$ & $c_{0}^{u}$ & $c_{0}^{r}$ & $c_{0}^{u}$ \\
\hline \multirow{2}{*}{$\eta=1$} & $2.98 \%$ & $9.68 \%$ & $3.28 \%$ & $9.99 \%$ & $0.96 \%$ & $7.53 \%$ \\
$\eta=2$ & $2.98 \%$ & $9.68 \%$ & $3.55 \%$ & $10.28 \%$ & $-0.62 \%$ & $5.83 \%$ \\
$\eta=4$ & $2.98 \%$ & $9.68 \%$ & $4.00 \%$ & $10.76 \%$ & $-3.13 \%$ & $3.16 \%$ \\
\hline
\end{tabular}

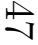

(a.2) Post-WTO

\begin{tabular}{|c|c|c|c|}
\hline & \multicolumn{3}{|c|}{ Cumulative Effect: Rural $(r)$ to Urban $(u)$} \\
\hline CRRA: & $\begin{array}{c}\text { Growth } \\
\left\{\gamma^{u}, \sigma^{r}, \psi^{r}\right\}\end{array}$ & $\begin{array}{c}\text { Risk } \\
\left\{\gamma^{u}, \sigma^{u}, \psi^{r}\right\}\end{array}$ & $\begin{array}{c}\text { Insurance Tech. } \\
\left\{\gamma^{u}, \sigma^{u}, \psi^{u}\right\}\end{array}$ \\
\hline & $c_{0}^{r} \quad c_{0}^{u}$ & & $c_{0}^{r} \quad c_{0}^{u}$ \\
\hline
\end{tabular}

$\eta=1 \quad 6.24 \% \quad 14.53 \% \quad 7.56 \% \quad 15.95 \% \quad 5.13 \% \quad 13.33 \%$

$\eta=2 \quad 6.24 \% \quad 14.53 \% \quad 8.87 \% \quad 17.36 \% \quad 5.29 \% \quad 13.50 \%$

$\begin{array}{lllllll}\eta=4 & 6.24 \% & 14.53 \% & 12.18 \% & 20.93 \% & 10.44 \% & 19.05 \%\end{array}$ (b) Earnings

(b.1) Pre-WTO

\begin{tabular}{|c|c|c|c|}
\hline & \multicolumn{3}{|c|}{ Cumulative Effect: Rural $(r)$ to Urban $(u)$} \\
\hline CRRA: & $\begin{array}{c}\text { Growth } \\
\left\{\gamma^{u}, \sigma^{r}, \psi^{r}\right\}\end{array}$ & $\begin{array}{c}\text { Risk } \\
\left\{\gamma^{u}, \sigma^{u}, \psi^{r}\right\}\end{array}$ & $\begin{array}{c}\text { Insurance Tech. } \\
\left\{\gamma^{u}, \sigma^{u}, \psi^{u}\right\}\end{array}$ \\
\hline & $c_{0}^{r} \quad c_{0}^{u}$ & $\begin{array}{ll}c_{0}^{r} & c_{0}^{u}\end{array}$ & $c_{0}^{r}$ \\
\hline
\end{tabular}

\begin{tabular}{lcccccc}
$\eta=1$ & $7.70 \%$ & $14.70 \%$ & $8.09 \%$ & $15.11 \%$ & $7.29 \%$ & $14.27 \%$ \\
$\eta=2$ & $7.70 \%$ & $14.70 \%$ & $8.52 \%$ & $15.57 \%$ & $7.11 \%$ & $14.08 \%$ \\
$\eta=4$ & $7.70 \%$ & $14.70 \%$ & $9.56 \%$ & $16.68 \%$ & $8.79 \%$ & $15.86 \%$ \\
\hline
\end{tabular}

(b.2) Post-WTO

\begin{tabular}{c|cc|cc|cc|}
\hline & \multicolumn{6}{|c|}{ Cumulative Effect: Rural $(r)$ to Urban $(u)$} \\
\hline CRRA: & $\begin{array}{c}\text { Growth } \\
\left\{\gamma^{u}, \sigma^{r}, \psi^{r}\right\}\end{array}$ & \multicolumn{2}{c}{$\begin{array}{c}\text { Risk } \\
\left\{\gamma^{u}, \sigma^{u}, \psi^{r}\right\}\end{array}$} & $\begin{array}{c}\text { Insurance Tech. } \\
\left\{\gamma^{u}, \sigma^{u}, \psi^{u}\right\}\end{array}$ \\
\hline & $c_{0}^{r}$ & $c_{0}^{u}$ & $c_{0}^{r}$ & $c_{0}^{u}$ & $c_{0}^{r}$ & $c_{0}^{u}$ \\
\hline$\eta=1$ & $3.63 \%$ & $11.71 \%$ & $5.70 \%$ & $13.94 \%$ & $4.06 \%$ & $12.18 \%$ \\
$\eta=2$ & $3.63 \%$ & $11.71 \%$ & $8.05 \%$ & $16.48 \%$ & $5.04 \%$ & $13.23 \%$ \\
$\eta=4$ & $3.63 \%$ & $11.71 \%$ & $13.18 \%$ & $22.01 \%$ & $10.94 \%$ & $19.59 \%$ \\
\hline
\end{tabular}

Notes: We take as reference scenario the actual estimates of growth, risk and insurance in the rural areas reported in section 4.2 for two measures of household income, disposable income in panel (a) and earnings in panel (b). We do this separately for the pre- and post-WTO sample periods. The columns headed with $c_{0}^{r}$ refer to the case where we keep the initial level of rural consumption in the counterfactual environment, while the columns headed with $c_{0}^{u}$ refer to the case where we replace the initial level of rural consumption for the initial level of urban consumption in the counterfactual environment. 
Figure 1: Public and Private Transfers (\% of Income), CHNS, China 1989-2009
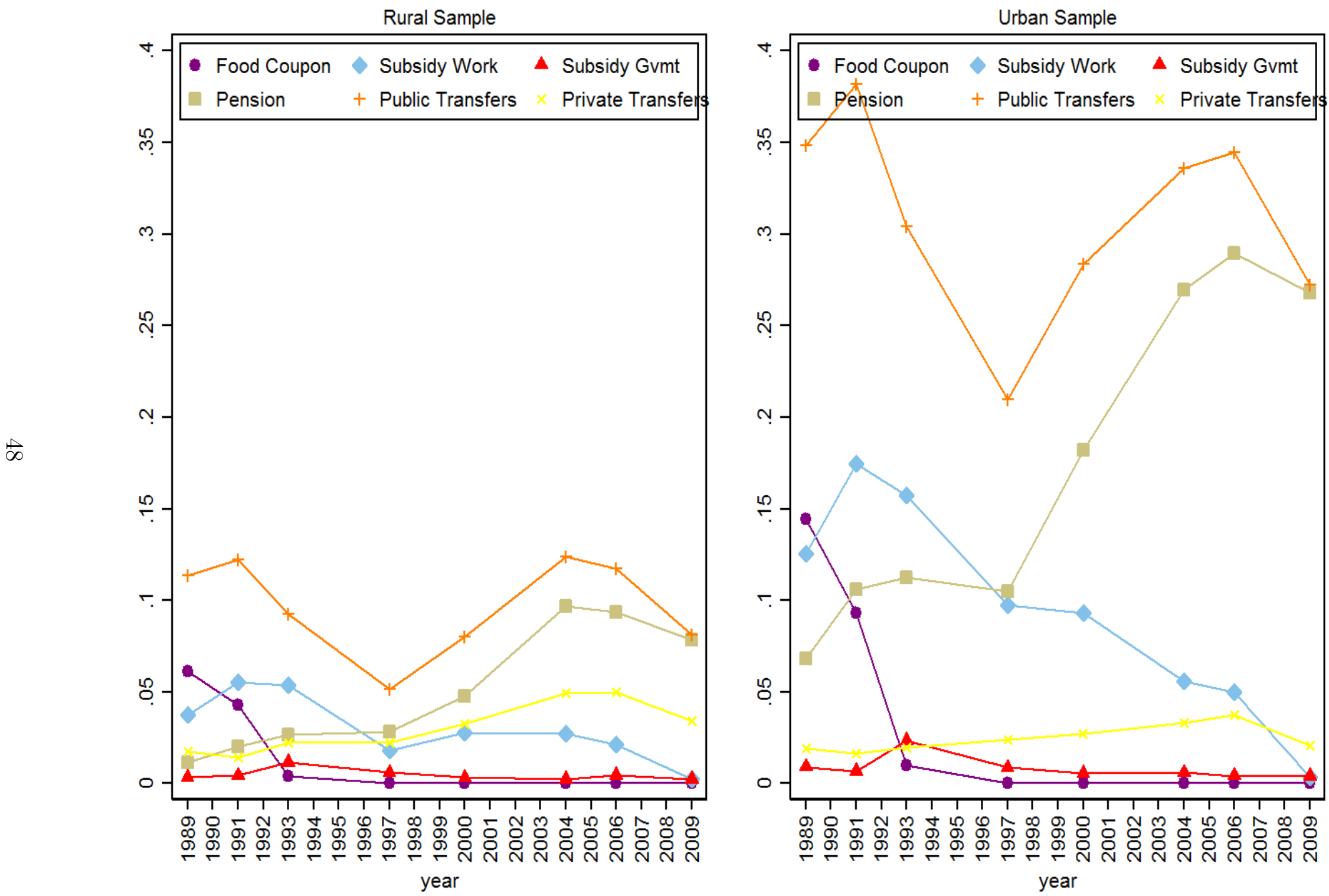

Notes: We plot the share of the aggregate amount of various public and private transfers in the aggregate income from 1989 to 2009 for the rural and urban CHNS sample separately. For the construction of the measure of transfers see section 3.1 in the text and section A.3 in the Appendix. For a discussion of the transfers system in China, see section 2. For a discussion of the role transfers plays in consumption insurance in China see section 4.2. 
Figure 2: Household Per Capita Net Income and Food Expenditure, CHNS and CSYB, China 1989-2009

Rural HH Disposable Income per Capita: CHNS vs CSYB

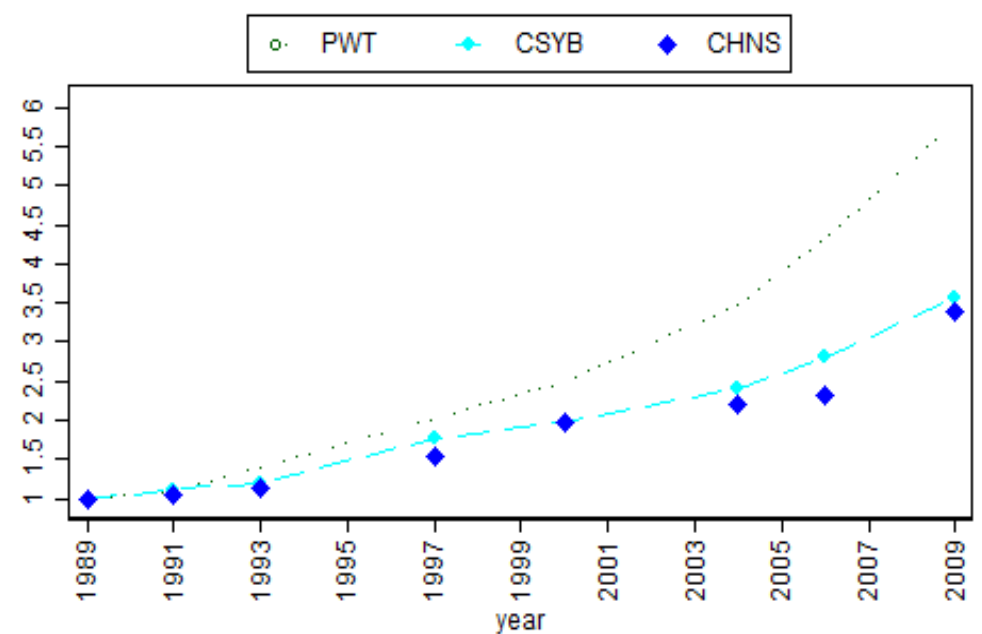

to

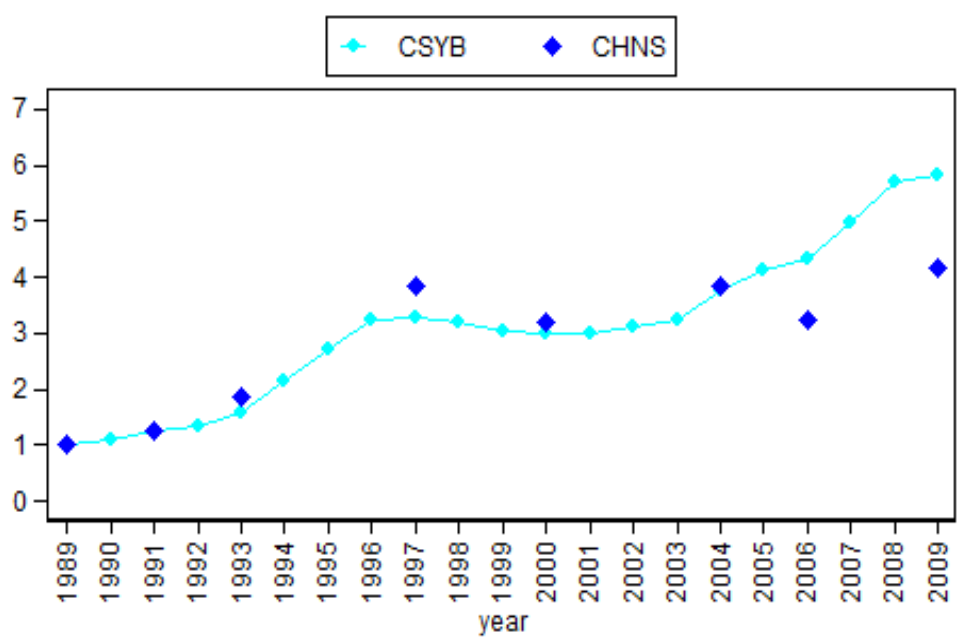

Urban HH Disposable Income per Capita: CHNS vs CSYB

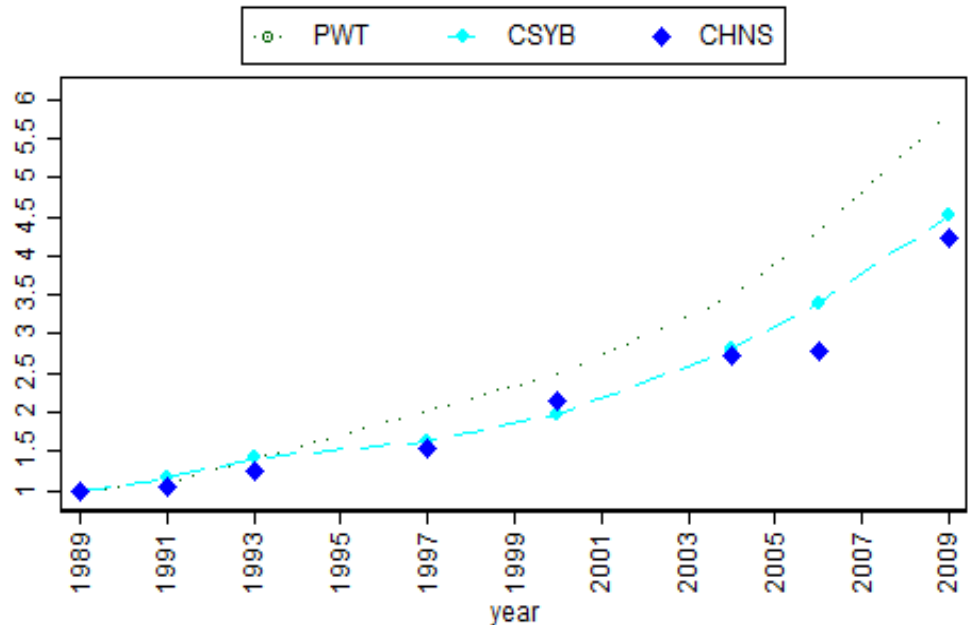

Urban HH Food Expenditure per Capita: CHNS vs CSYB

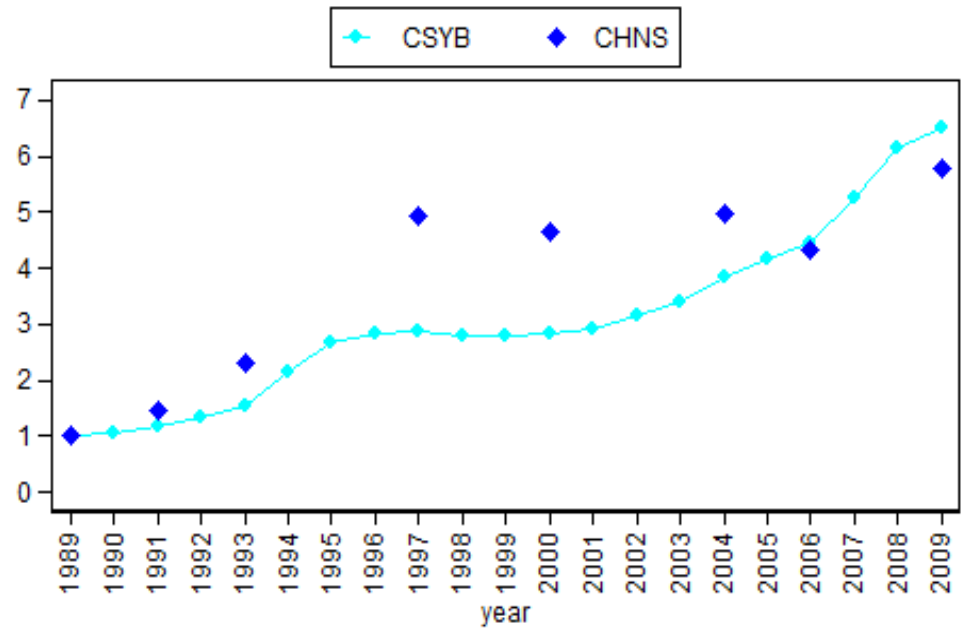

Notes: The top figures show the household per capita net income from the CHNS against the household per capita net income from the CSYBs, for rural and urban China. The net income in the CHNS is constructed by deducting from the disposable income the value of in-kind transfers. The rural and urban household per capita net income from the CSYBs are derived from the provincial counterparts weighted according to the population weights in the CHNS. Real GDP per capita from the Penn World Table is also included in the two figures. The bottom two panels show the household per capita food expenditure from the CHNS and from the CSYBs. The food expenditure in the CHNS is constructed by deducting from the value of diet the value of food coupons and food gifts. All values are normalized to 1 in 1989. For a discussion on the data construction, see section 3.1 . 
Figure 3: Adult-Equivalent Consumption and Income Inequality, Variance of Logs, CHNS, China 1989-2009

Consumption and Income

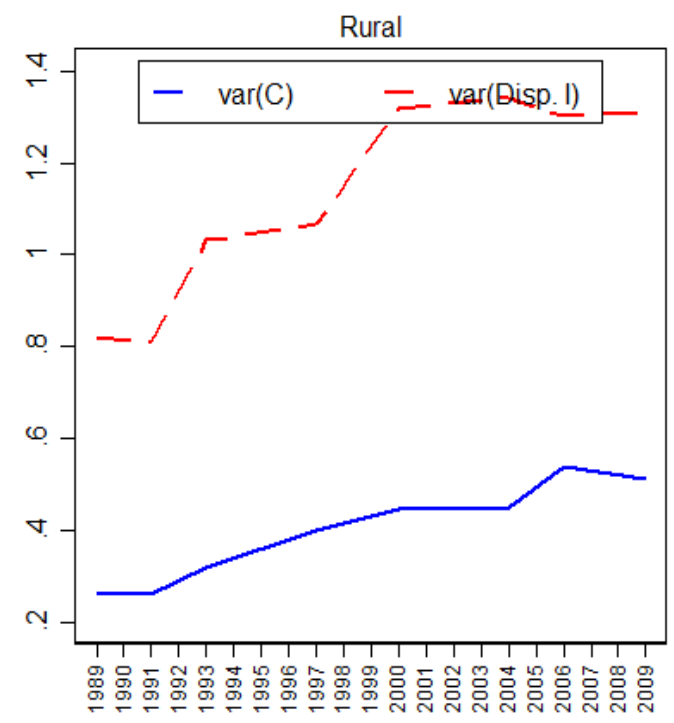

Household Structure

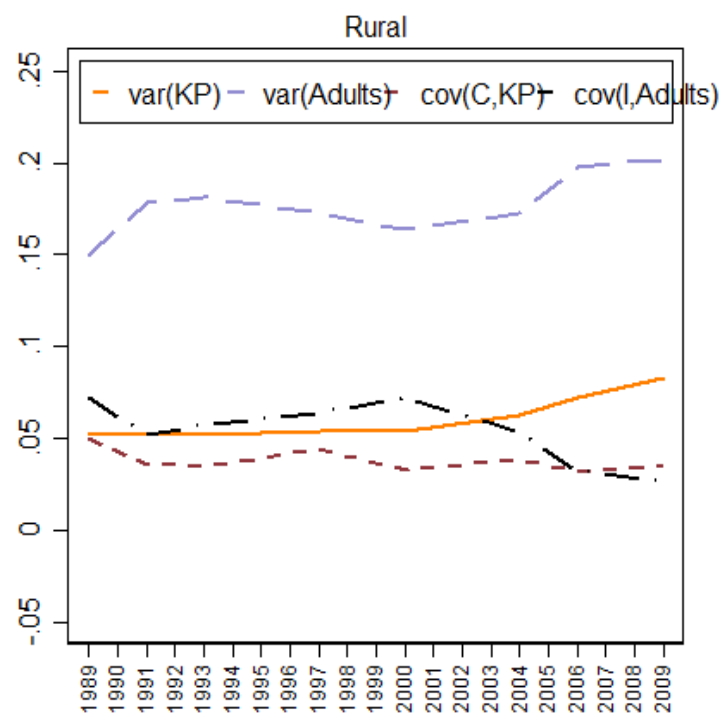

Adult-Equiv, Normalized at 1989

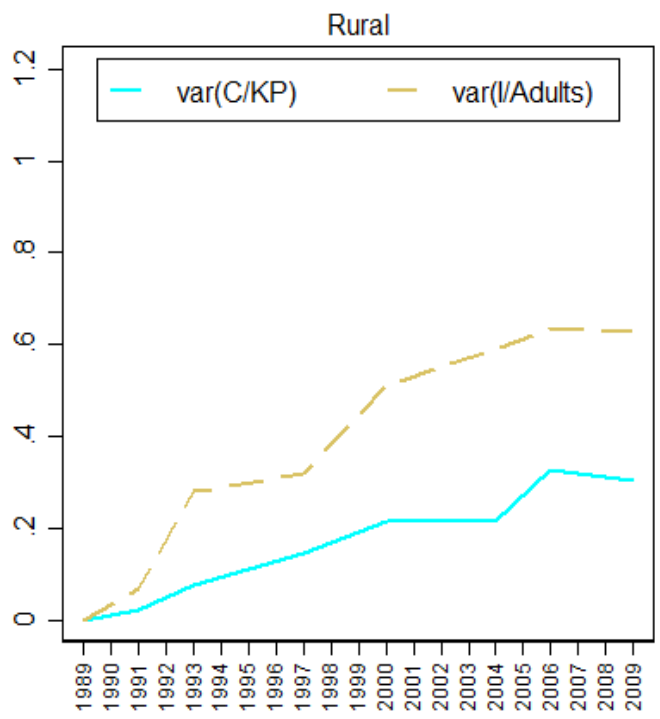

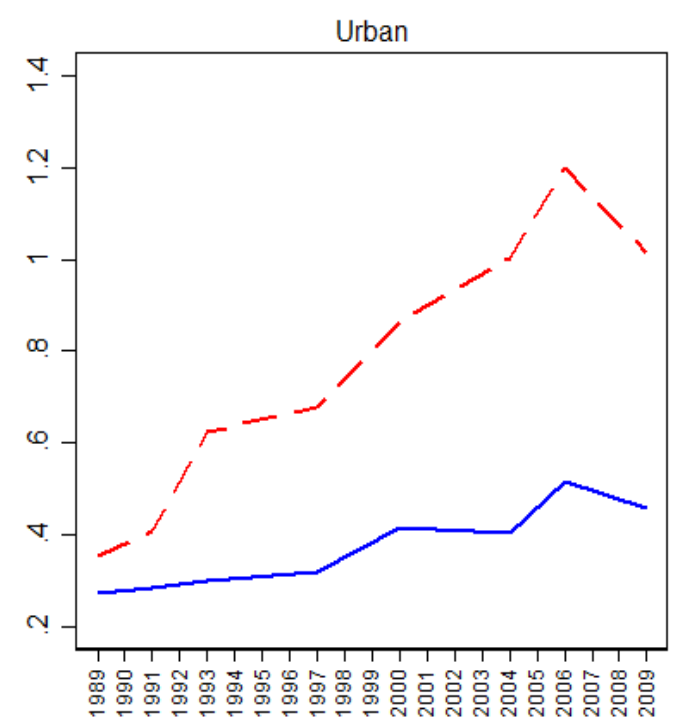
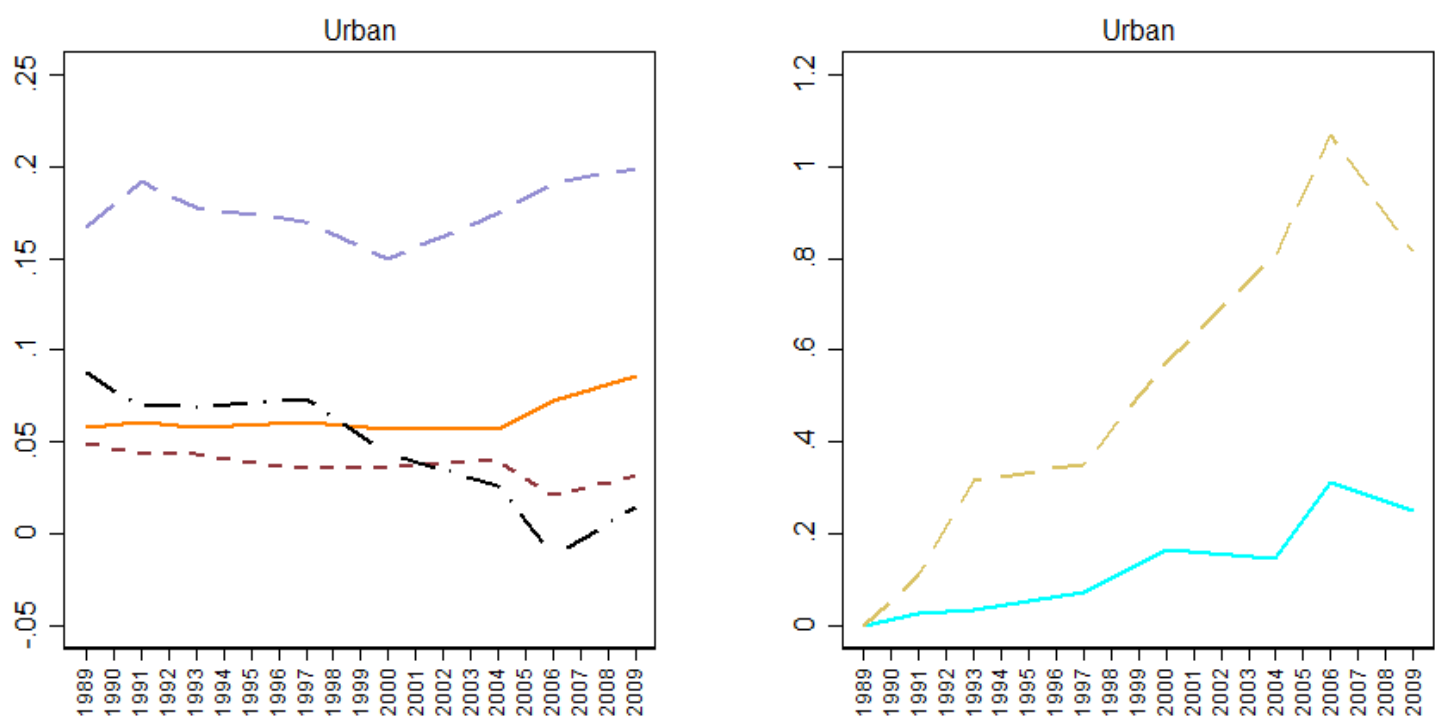

Notes: The left column shows the evolution of the variance of logged household consumption and disposable income from 1989 to 2009 . The middle column shows the evolution of the variance of the NAS adult-equivalence scale and the number of adults, the covariance of the former with household consumption and the covariance of the latter with household disposable income. The right column shows the evolution of the variances of adult-equivalent consumption and disposable income normalized to 0 in 1989. For a discussion on the facts, see section 3.2. 
Figure 4: Residual Consumption and Income Inequality, Variance of Logs, CHNS, China 1989-2009

\section{Raw and Residual Inequality}

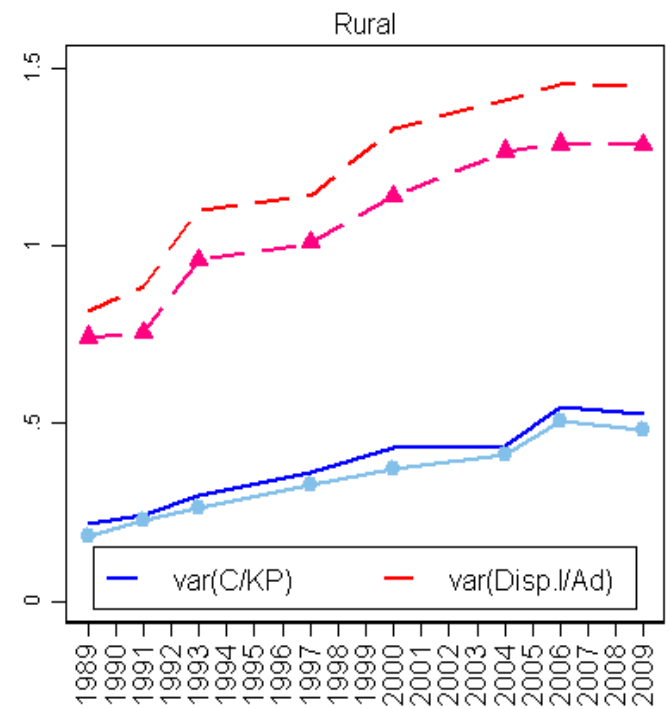

$\stackrel{c}{\oplus}$

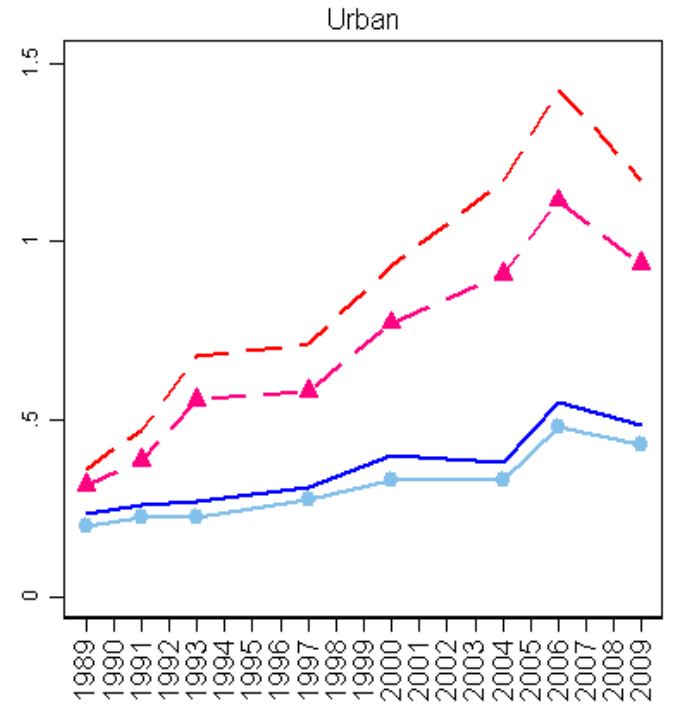

Residual Inequality, Normalized at 1989
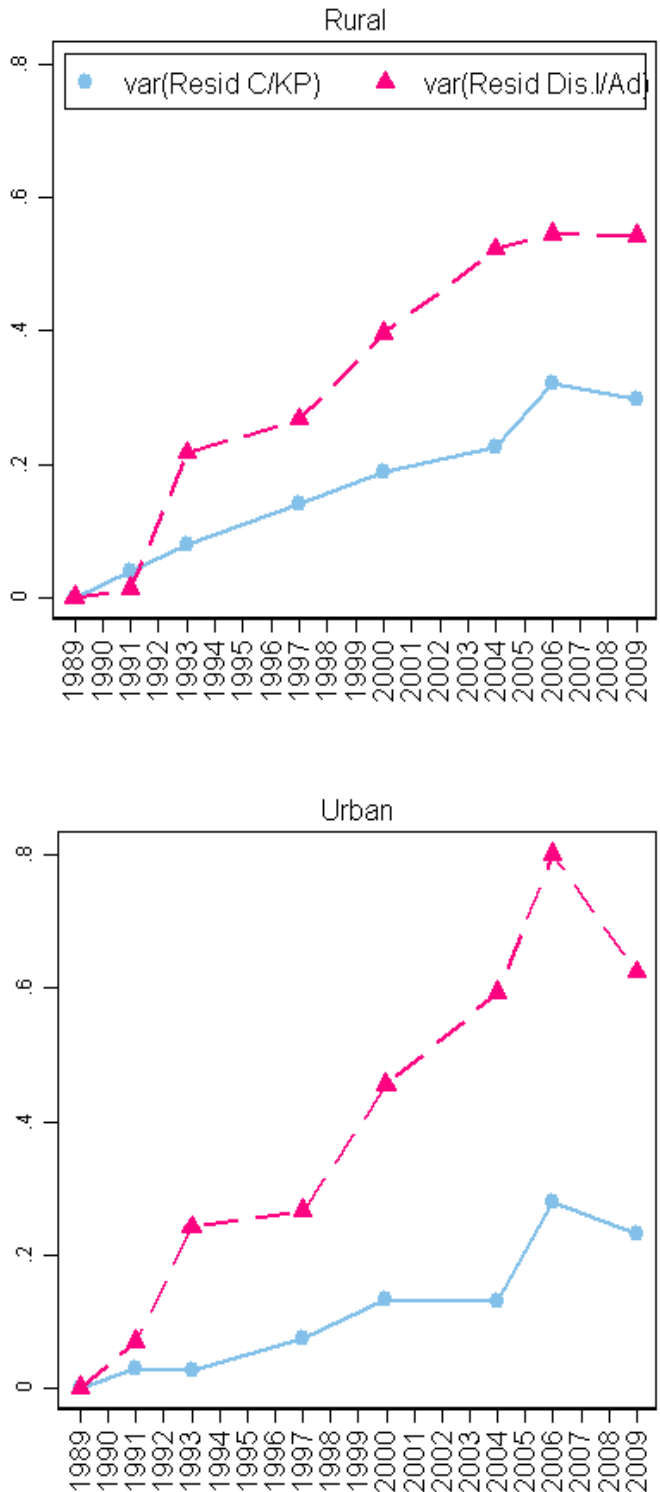

Covariance of Residual Cons. and Inc.
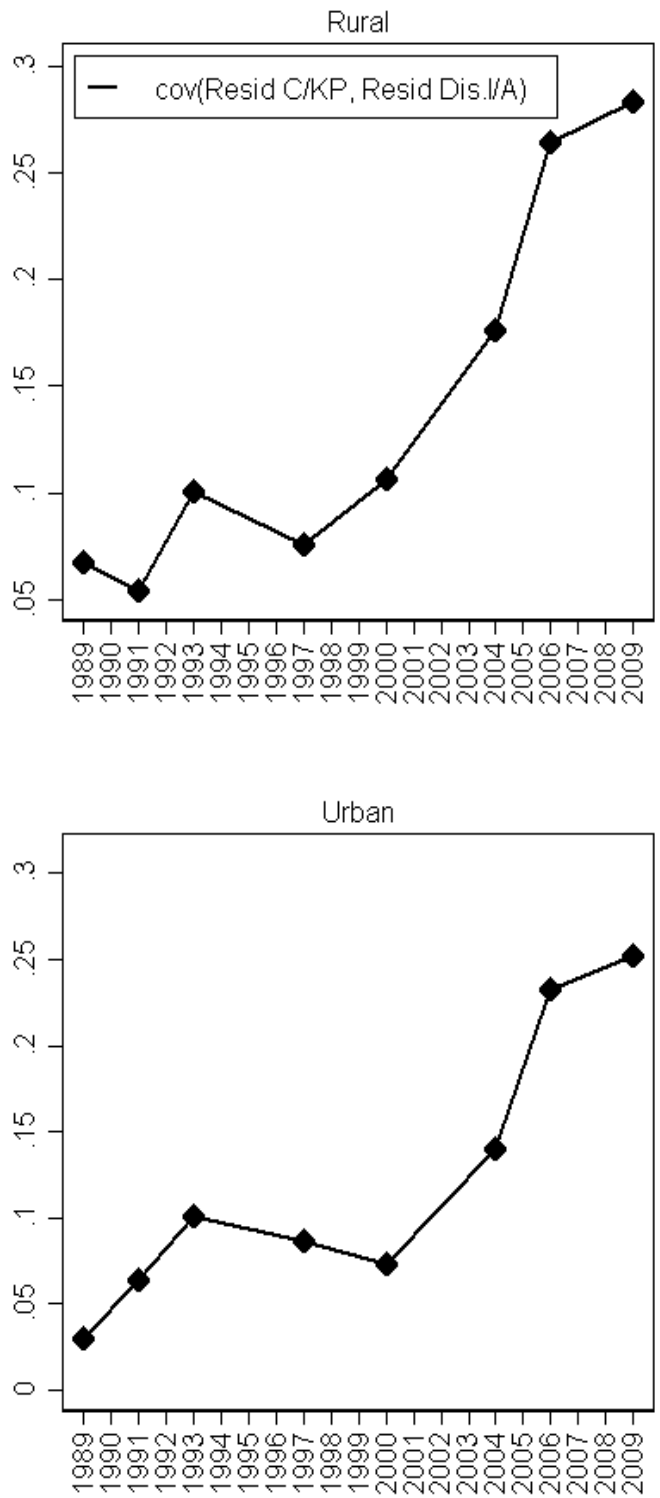

Notes: The left column shows the evolution of the raw and residual inequality of the adult-equivalent consumption and disposable income from 1989 to 2009. The middle column shows the evolution of the residual inequality of consumption and disposable income, normalized to 0 in 1989 , from 1989 to 2009 . The right column shows the evolution of the covariance of residual adult-equivalent consumption and disposable income from 1989 to 2009 . For a discussion on the facts, see section 3.2. 
Figure 5: Welfare Preserving Policy Experiments: Growth Reforms vs. Stabilization Policies vs. Social Insurance Policies
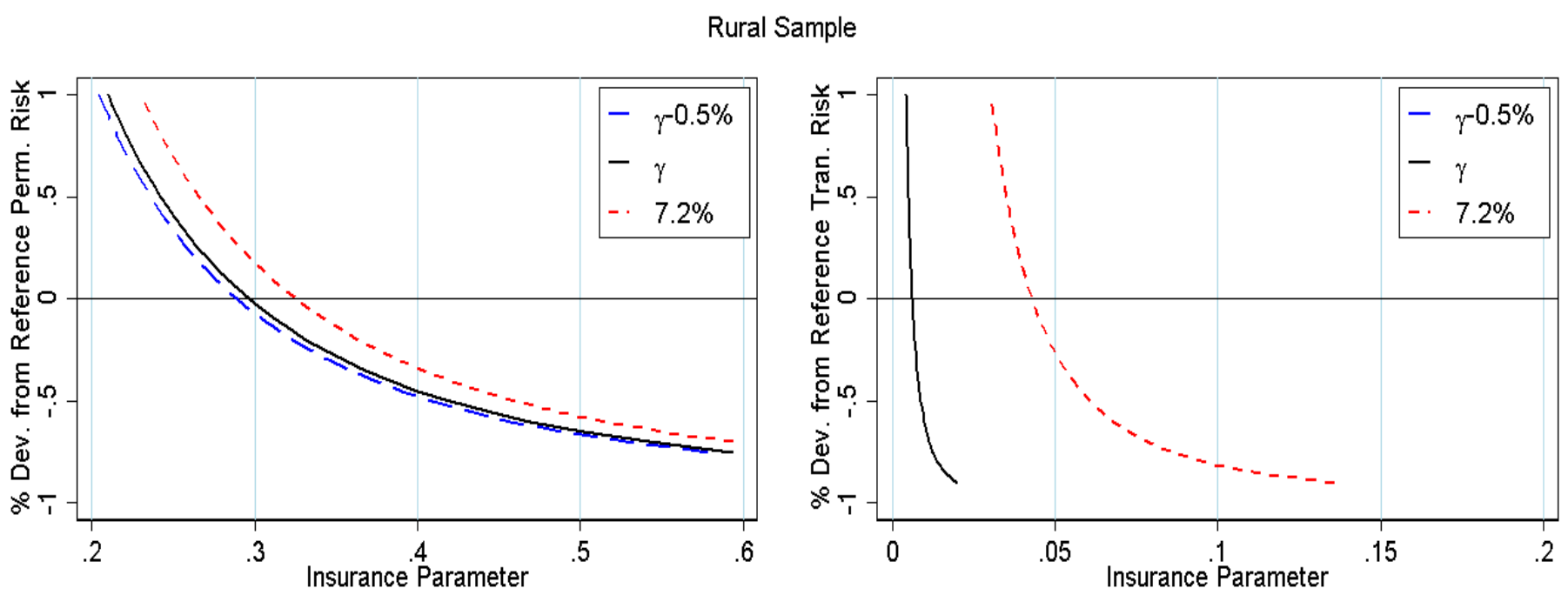

Urban Sample
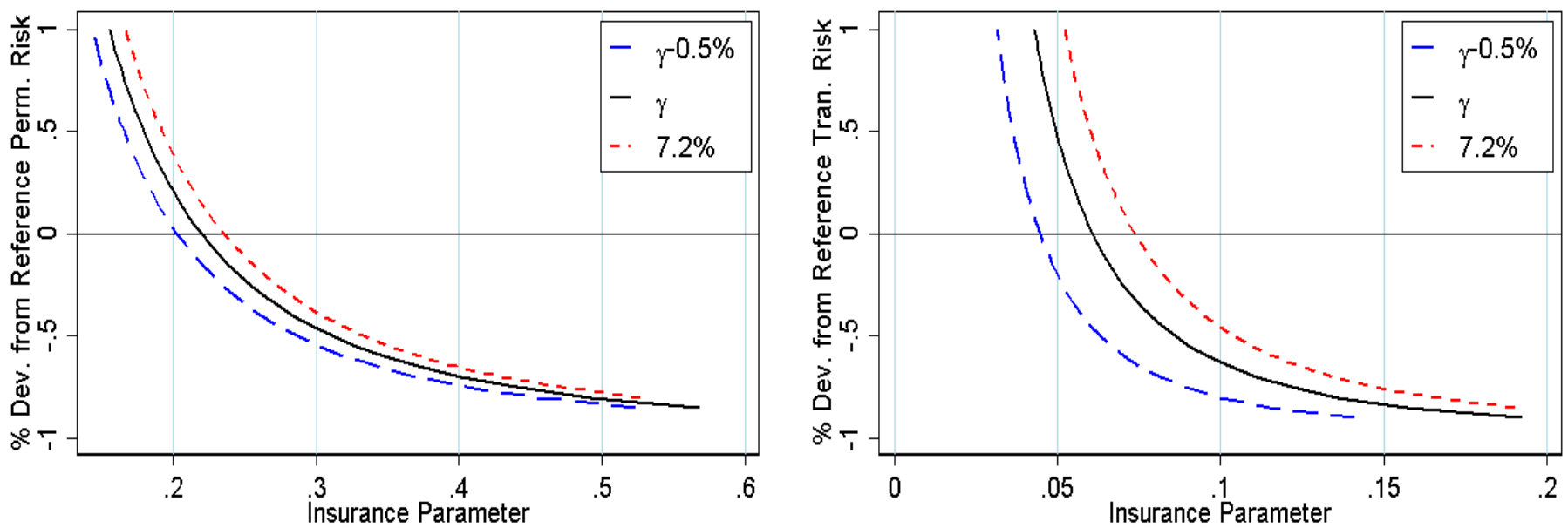

Notes: In each panel all combinations of the variance of income shocks (in percentage deviations from reference estimates, vertical axis) and the level of insurance (horizontal axis) preserve status-quo/reference welfare and each curve consists of the combinations that preserve status-quo/reference welfare under a specific growth scenario. We entertain three income growth scenarios: the reference income growth rate minus 50 basis points, the reference and an optimistic $7.2 \%$. For a discussion of the policy experiment, see section 7 . The average rural income growth that defines our reference environment is $5.20 \%$ and the urban income growth rate is $6.71 \%$, i.e., the post-WTO average income growth rates. The estimated reference annualized variance of permanent shocks, averaged over 2001 to 2009, is .1305 in rural areas and .0946 in urban areas. The numbers for the annualized variance of transitory shocks are .4295 in rural areas and .2580 in urban areas. Finally, the estimated reference insurance parameters in rural and urban areas are taken to be the same as the $\left(\psi_{\zeta}^{\text {post }}, \psi_{\varepsilon}^{\text {post }}\right)$ in our benchmark. 